This work has been accepted to Journal of Climate. The AMS does not guarantee that the copy provided here is an ac-

\title{
Radiative feedbacks on land surface change and associated tropical
}

\author{
precipitation shifts
}

Department of Earth and Planetary Science, University of California, Berkeley, Berkeley, CA, 
Climate and Ecosystem Sciences Division, Lawrence Berkeley National Laboratory, Berkeley,

CA, USA

${ }_{22}^{*}$ Corresponding author address: Marysa M. Laguë, Center for Hydrology Coldwater Lab, Univer${ }_{23}$ sity of Saskatchewan, Canmore, AB, Canada

${ }_{24}$ E-mail: mlague@uw.edu 


\section{ABSTRACT}

${ }_{31}$ in global land albedo, the albedo forcing and a positive water vapor feed-

Changes in land surface albedo and land surface evaporation modulate the atmospheric energy budget by changing temperatures, water vapor, clouds, snow and ice cover, and the partitioning of surface energy fluxes. Here idealized perturbations to land surface properties are imposed in a global model to understand how such forcings drive shifts in zonal mean atmospheric energy transport and zonal mean tropical precipitation. For a uniform decrease back contribute roughly equally to increased energy absorption at the top of the atmosphere (TOA), while radiative changes due to the temperature and cloud cover response provide a negative feedback and energy loss at TOA. Decreasing land albedo causes a northwards shift in the zonal mean intertropical convergence zone (ITCZ). The combined effects on ITCZ location of all atmospheric feedbacks roughly cancel for the albedo forcing; the total ITCZ shift is comparable to that predicted for the albedo forcing alone. For an imposed increase in evaporative resistance that reduces land evaporation, low cloud cover decreases in the northern mid-latitudes and more energy is absorbed at TOA there; longwave loss due to warming provides a negative feedback on the TOA energy balance and ITCZ shift. Imposed changes in land albedo and evaporative resistance modulate fundamentally different aspects of the surface energy budget. However, the pattern of TOA radiation changes due to the water vapor and air temperature responses are highly correlated for these two forcings because both forcings lead to near-surface warming. 


\section{Introduction}

Changes in land surface properties, such as those associated with changes in vegetation, modulate fluxes of energy and water between land and the overlying atmosphere (Charney et al. 1975; Shukla and Mintz 1982; Koster et al. 2004, 2006; Davin et al. 2010; Laguë et al. 2019). Changes in land surface properties can directly modify surface temperatures by re-partitioning surface energy fluxes between sensible and latent components (Lee et al. 2011; Devaraju et al. 2018; Laguë et al. 2019). By modifying the overlying atmosphere, land surface changes can also indirectly alter local surface climate by changing radiation and surface turbulent fluxes in ways that constitute feedbacks on the original land surface perturbation (Betts et al. 1996). Furthermore, land-driven atmospheric changes can lead to changes in terrestrial climate both in the region of the original land surface change and in regions far removed from that initial change (Charney et al. 1975; Bonan et al. 1992; Swann et al. 2012; Laguë and Swann 2016; Devaraju et al. 2018; Winckler et al. 2018; Laguë et al. 2019).

Changes in land surface properties modify climate by modulating the flux of energy between land and the base of the atmosphere. Surface albedo directly influences the solar energy absorbed by land, with darker land such as forests absorbing more sunlight than brighter land such as deserts (Budyko 1961, 1969; Payne 1972; Bonan 2008, and references therein). The land surface has a small heat capacity compared to the ocean and does not efficiently move energy laterally (Cess and Goldenberg 1981; North et al. 1983; Milly and Shmakin 2002; Bonan 2008). Thus, over annual timescales, changes in solar and longwave energy absorbed by land cause changes in longwave radiation, sensible heat, and latent heat emitted by land; that is, the land surface energy budget is closed over sufficiently long timescales such as the annual cycle (Manabe 1969; Budyko 1982). Latent heat flux from land to the atmosphere is modulated not only by surface water availability 
and atmospheric water vapor demand, but also by physical properties of the land surface (Budyko 1961, 1969). For example, vegetation can actively modify the flux of water from land to the atmosphere by regulating transpiration through the opening and closing of stomata (leaf pores that control gas exchange) (Sellers et al. 1996).

Changes in land surface albedo and evaporation have been demonstrated to be capable of driving large-scale shifts in atmospheric circulation (Charney et al. 1977; Shukla and Mintz 1982). Davin et al. (2010) explored the effects of albedo, evaporation, and roughness of a completely forested vs. grass-covered world, while Swann et al. (2012) demonstrated how mid-latitude forest cover can shift the location of the Intertropical Convergence Zone (ITCZ) in a global climate model. Such changes in global circulation can be understood, in part, using the vertically integrated atmospheric energy budget. For example, changes in surface ice cover, vegetation, or idealized energy sources have been shown to modify large-scale atmospheric circulation and tropical precipitation, with the zonal mean location of the ITCZ shifting towards the energy-rich hemisphere (Chiang and Bitz 2005; Broccoli et al. 2006) or, more precisely, toward the hemisphere containing the anomalous positive energy source (Kang et al. 2008, 2009; Swann et al. 2012; Laguë and Swann 2016; Kang 2020; Geen et al. 2020).

To understand the atmospheric response to an imposed change in the climate system, it can be useful to decompose the response into that produced directly by the forcing and that arising from individual feedbacks. For example, increased atmospheric carbon dioxide concentrations directly affect longwave radiation (the forcing) and initiate feedbacks by other aspects of the climate system (e.g. changes in cloud cover or sea ice extent) which further modify shortwave (SW) and longwave (LW) radiation at both the top of the atmosphere (TOA) and the surface (Andrews et al. 2012). For low-latitude rainfall changes, these feedbacks can be large compared to the forcing (Kang et al. 2009; Cvijanovic and Chiang 2013), making it difficult to understand and predict how 
an imposed land surface change which modifies the atmospheric energy budget will alter local and remote surface climate.

In this study, we investigate how idealized changes in land surface properties modify largescale atmospheric circulation and precipitation, both through their direct effect on fluxes of energy into the atmosphere and through radiative feedbacks. We first use climate model simulations to study how global-scale changes in land surface albedo and evaporative resistance modify the atmospheric energy source (i.e. the net flux of energy into the atmosphere through its top and bottom boundaries). While many more studies have focused on the influence of land surface albedo on climate (e.g. Charney et al. 1977; Dickinson 1983; Broccoli and Manabe 1987), evaporative resistance is also important (e.g. Shukla and Mintz 1982; Sellers et al. 1996; Laguë et al. 2019; Zarakas et al. 2020). Evaporative resistance controls the surface latent heat flux for a given vapor pressure deficit of surface air, and is a bulk proxy for many surface and vegetative processes that control water vapor flux.

We attribute changes in the atmospheric energy source to the direct effect of the imposed land surface change (in albedo or evaporative resistance) and to feedbacks resulting from (i) albedo changes due to snow and ice cover, (ii) changes in atmospheric water vapor, (iii) changes in temperatures, and (iv) changes in cloud cover. Each of these components of the change in the atmospheric energy source can, through the vertically integrated atmospheric energy budget, be directly associated with a change in atmospheric energy transport. Since, in Earth's tropics, both precipitation and atmospheric energy transport are primarily accomplished by time-mean overturning circulations, this allows us to attribute changes in tropical circulation and tropical precipitation to the imposed land surface forcing and the feedbacks. 


\section{Methods}

\section{a. Model}

We use a modified version of the Community Earth System Model (CESM) (Hurrell et al. 2013), consisting of the Community Atmosphere Model v. 5 (CAM5) coupled to a slab ocean model, the CICE5 interactive sea ice model (Bailey et al. 2018), and a simplified land model. The slab ocean allows sea surface temperatures (SSTs) to change but uses prescribed ocean heat transport (Neale et al. 2012); this allows atmospheric circulation more freedom to change over both land and oceans than in a fixed-SST simulation. The prescribed ocean heat transport is identical across all simulations. The ocean is a large source of variability in the real world and in models with dynamic ocean components; the slab ocean avoids introducing oceanic variability to our simulations, but also can introduce biases in the modelled response to a forcing, as it does not allow for ocean circulation and heat transport to change. Instead of the Community Land Model (CLM) (Oleson et al. 2013; Lawrence et al. 2019), we use the Simple Land Interface Model (SLIM) (Laguë et al. 2019), which allows us to explicitly control individual land surface properties in a way that is not possible with more complex land surface models such as CLM. Simulations are run at roughly $2^{\circ}$ horizontal resolution.

\section{b. Simulations}

Two land surface properties are perturbed for this study: albedo and evaporative resistance. Albedo is a measure of the fraction of incident shortwave radiation that the land surface reflects, while evaporative resistance modifies the difficulty of evaporating water from land. In the context of vegetation, albedo is modulated by leaf color, leaf angle, and leaf area; evaporative resistance 
is a combined result of soil moisture, root depth, leaf area, and stomatal conductance. In SLIM, both surface properties are directly controlled by the user.

We modify the prescribed, snow-free albedo of the land surface for visible shortwave radiation (both direct and diffuse streams). A portion of the total modelled shortwave radiation incident upon the land surface occurs in the near-infrared (near-IR), but we hold the snow-free land surface albedo in the near-IR fixed across all simulations. As a result, an imposed change of 0.1 to the albedo in the visible spectrum results in a total (combined near-IR and visible) albedo change of roughly 0.05 (figure 1). We only modify the land surface albedo over non-glaciated regions. The total land surface albedo can be modified by the presence of snow, which masks the bare-ground albedo and results in a brighter surface; as such, the actual change in albedo that affects radiation is smaller than the snow-free albedo change imposed on the land surface (figure 1).

The evaporative resistance that we modify in SLIM modulates the difficulty of evaporating water from land. The hydrology in SLIM is represented by a bucket at each land point. To evaporate water from the bucket, there is a combined resistance due in part to how full the bucket is (analogous to soil moisture), and in part to the imposed evaporative resistance at each point (analogous to properties such as vegetation root depth or stomatal conductance). It is this second resistance term which we modify in our simulations; the soil moisture is free to evolve. Actual changes in terrestrial evaporation can occur directly from the imposed change in evaporative resistance, or as a result of changes in precipitation and soil moisture, changes in energy input from the atmosphere, changes in atmospheric vapor pressure deficit, changes in near-surface wind speed, and changes in snow cover.

Three simulations are used in this study. Each simulation is run for a total of 50 years, with the first 20 years discarded to allow the model time to spin up. Note that the model simulations used in this study are a subset of the same simulations used in Laguë et al. (2019). 
The first "baseline" simulation uses moderate values for land surface albedo $(\alpha=0.2)$ and evaporative resistance $\left(r_{s}=100 \mathrm{~s} / \mathrm{m}\right)$. The second simulation explores the effect of making land darker $\left(\alpha=0.1, r_{s}=100 \mathrm{~s} / \mathrm{m}\right)$, while the third explores the effect of making it harder to evaporate water from land $\left(\alpha=0.2, r_{s}=200 \mathrm{~s} / \mathrm{m}\right)$. The magnitude of imposed changes in albedo and canopy-level evaporative resistance explored here are loosely comparable to the differences between forests and grasslands (see Bonan 2016, and references therein). Given the uncertainty and variability in properties of a particular vegetation type, we do not aim to impose changes that are exactly representative of a specific vegetation change.

All other land surface properties are identical across simulations, and across space. That is, all simulations have the same spatially uniform values for aerodynamic roughness $(0.1 \mathrm{~m})$, the capacity of land to hold water $(200 \mathrm{~mm})$, soil thermal properties, etc. Glaciated land points have thermal and radiative properties consistent with ice (Laguë et al. 2019).

\section{c. Approach}

Here, we outline the general approach used in this study. Details on specific calculations are provided in the Appendix. We modify each of the two land surface properties (albedo and evaporative resistance) in isolation. Each change in land surface property drives a change in net TOA radiation $\left(T O A_{n e t}\right)$, a change in zonal mean cross-equatorial atmospheric heat transport, and a shift in the zonal mean location of the ITCZ.

Using a combination of model output and radiative kernels for albedo, temperature, and water vapor, we decompose the total change in TOA radiation into the change in TOA $S W$ directly due to the imposed change in land surface albedo, the change in TOA $S W$ due to changes in albedo from changes in snow/ice cover, the change in TOA $L W$ due to changes in surface temperature and atmospheric temperatures, the changes in TOA $S W$ and $L W$ due to changes in water vapor, and the 
changes in TOA $S W$ and $L W$ due to changes in cloud cover. The same radiative kernel is used to analyze both sets of simulations, yielding a distinct TOA response for each simulation because the effect of the imposed changes in land surface albedo and evaporative resistance generate distinct changes in surface temperatures, cloud cover, snow/ice cover, and atmospheric temperatures and moisture.

We meridionally integrate $T O A_{n e t}$, under the assumption that atmospheric energy storage is negligible on annual time scales, to calculate cross-equatorial atmospheric energy transport $A E T_{e q}$, and estimate the linear relationship between $A E T_{e q}$ and the zonal-mean location of the ITCZ. We measure the zonal-mean ITCZ location as the latitude $\phi_{p}$ that is the center of mass of the precipitation distribution between $20^{\circ} \mathrm{S}-20^{\circ} \mathrm{N}$. Using the individual contribution to $\triangle T O A_{\text {net }}$ from each surface or atmospheric process resulting from the imposed change in land surface property (e.g. the change in albedo from changes in snow/ice, or the change in water vapor), we determine the $\triangle A E T_{e q}$ that would result from that individual component of the $T O A_{n e t}$ response alone. We then leverage the derived relationship between $A E T_{e q}$ and $\phi_{p}$ to attribute portions of the total modelled shift in the ITCZ to each individual atmospheric and surface process. The practice of meridionally integrating anomalous TOA energy sources to obtain an $A E T_{e q}$ change and then an ITCZ shift follows Kang et al. (2008), and using this procedure to estimate radiative feedbacks follows Peterson and Boos (2020).

We follow the methodologies laid out in Soden et al. (2008), Shell et al. (2008), and Pendergrass et al. (2018) to decompose the response of TOA radiation into components associated with changes in imposed land surface albedo, changes in albedo due to changes in snow and ice, changes in water vapor, changes in surface and air temperatures, and changes in cloud cover.

In one set of simulations we perturb the snow-free surface albedo with an imposed change in albedo $\Delta \alpha_{i}$ (figure 1c,d). In the second set of simulations (where evaporative resistance is 
perturbed), snow-free albedo is held fixed. However, in both sets of simulations the total modelled surface albedo $\alpha_{m}$ (the albedo the atmosphere "sees", figure 1a) can be modified by changes in snow and ice. Thus, we separate our analysis of the TOA $S W$ response to the albedo change into two parts: the response to the imposed snow-free albedo change $\Delta \alpha_{i}$ and the change in monthly albedo due to changes in snow and ice $\Delta \alpha_{s}$, which we calculate as the residual of the total simulated albedo change minus the imposed albedo change, i.e. $\Delta \alpha_{s}=\Delta \alpha_{m}-\Delta \alpha_{i}$ (figure 1b). Further details of the albedo decomposition are included in the supplemental materials. The effect of changes in temperatures $(T)$ and water vapor $(q)$ on TOA radiation can be calculated directly from the radiative kernels and the modelled changes in $T$ and $q$. The effect of changes in cloud cover on TOA radiation is calculated as a residual of the total modelled change in TOA radiation and the changes due to albedo, $T$, and $q$.

\section{Results}

Decreasing land surface albedo and increasing land surface evaporative resistance both generate changes in the TOA energy balance with distinct spatial and seasonal patterns (figure 3). Decreasing land surface albedo results in more energy absorbed at the TOA over most land regions, particularly during local summer when insolation is high, while increasing land surface evaporative resistance modifies the TOA energy budget mostly in the northern mid-to-high latitudes during boreal summer. Decreasing land albedo and increasing land evaporative resistance both lead to overall more energy absorbed at the TOA over the Northern Hemisphere, though for different reasons which are explored below.

The land albedo and evaporative resistance changes also produce changes in precipitation over both land and ocean across the globe. Past studies have demonstrated that hemispheric imbalances in atmospheric energy sources lead to shifts in the ITCZ towards the positive energy source 
anomaly (e.g. Chiang and Bitz 2005; Broccoli et al. 2006; Kang et al. 2008; Swann et al. 2012; Laguë and Swann 2016; Kang 2020). In our simulations, changes in land surface albedo and evaporative resistance both lead to northward shifts in the ITCZ (figure 2; the general pattern of positive precipitation anomalies to the north of the equator and negative anomalies to the south indicate a northward shift of the tropical precipitation maximum). Here, we investigate the mechanisms contributing to the change in the TOA energy budget, and quantify the association between changes in the TOA radiative balance and changes in the atmospheric energy transport and zonal mean tropical precipitation. We focus these analyses on the annual mean.

\section{a. Decreasing Land Surface Albedo}

The spatially uniform decrease in snow-free land albedo has a spatially non-uniform impact on $T O A_{n e t}$. Darkening land results in more $S W$ being absorbed by Earth over most land areas, while over oceans and parts of the northern high-latitudes, more energy is lost by the Earth system (figure 3a). The peak anomalous energy gain resulting from the decreased land albedo is found in the tropics in the annual mean, with smaller increases in the mid-latitudes.

To understand the mechanisms through which a spatially uniform change in land surface albedo causes a spatially non-homogeneous and non-local change in TOA radiation, we decompose the response into a forcing and several feedbacks, each of which impact the TOA flux of shortwave $(S W)$ or longwave $(L W)$ radiation. For our analysis of changes in TOA energy fluxes, all fluxes ( $S W$ and $L W$ ) are defined to be positive downwards such that positive anomalies indicate more energy into the Earth system. 


\section{1) Albedo Forcing}

The imposed decrease in land surface albedo directly forces an increase in absorbed solar radiation at the surface, and in turn reduces the amount of $S W$ leaving the atmosphere at the TOA. Using the all-sky (i.e. including the effects of clouds) radiative kernel for albedo for CAM5 (Pendergrass et al. 2018), we calculate how our imposed change in land surface albedo directly modifies TOA $S W$ assuming temperatures, water vapor, snow and ice cover, and cloud cover do not change. The imposed decrease in land surface albedo causes an increase in net TOA $S W$ radiation over all non-glaciated land areas (that is, everywhere the albedo was directly changed; figure 4a). Within snow-free land regions, the spatial pattern in the change in TOA $S W$ radiation comes predominantly from the spatial pattern of the radiative kernel itself, which reflects the pattern of insolation, cloudiness, and clear-sky optical depth (figure S1). From the kernel, the increase in absorbed TOA $S W$ for a spatially uniform decrease in land albedo is largest in low latitudes, where incident solar radiation is highest and the annual mean atmospheric path length for downwelling shortwave is smallest. The same albedo change imposed on regions with climatologically high cloud cover (e.g. the Maritime Continent) has a smaller impact on TOA $S W$ than regions at a similar latitude with less cloud cover, as less $S W$ reaches the surface in those regions. The direct forcing of the imposed albedo change is calculated here specifically for snow-free albedo, i.e. how the TOA $S W$ would be affected in the absence of snow. However, land surface albedo in higher latitudes is masked by snow for part of the year; the change in TOA radiation because of changes in snow and ice is captured in the albedo feedback term discussed next.

\section{2) Albedo FeEdBACK}

We define albedo feedbacks as changes in TOA $S W$ radiation due to changes in snow and ice cover, which themselves result from changes to the climate system driven by our imposed change 
in land surface property. Decreasing land surface albedo leads to warming near the land surface, causing sea ice loss and changes in snow cover in the high latitudes (figure 1b). Using the radiative kernel for albedo, we can quantify the effect of albedo changes resulting from changes in snow and ice on TOA $S W$. The albedo feedback on the imposed decrease in snow-free land albedo is positive (i.e. more $S W$ absorbed at the TOA) over regions of snow and sea ice loss, with most of the changes occurring in the northern high latitudes (with some loss of sea ice along the ice edge of Antarctica; figure 4b).

\section{3) WATER VAPOR FEEDBACKS}

Decreased land surface albedo can modify atmospheric water vapor by modulating evaporation from the land surface, winds that transport water vapor, and the saturation vapor pressure (via air temperature changes). Decreasing land albedo leads to more water vapor over tropical land in our model, with atmospheric temperatures and specific humidities both generally increasing over land. There is also a meridional dipole pattern in precipitable water over tropical oceans reflecting a northwards shift in the ITCZ and a change in the humidity of the subtropical dry zones (figure 5). In idealized aquaplanet models, the relative humidity of the subtropical dry zones increases in the hemisphere in which a positive energy source is imposed and decreases in the subtropical dry zones on the other side of the equator, amplifying the more traditional fixed-relative humidity water vapor feedback (Peterson and Boos 2020); this also seems to occur in our model in response to land albedo changes. The only statistically significant changes in $S W$ at the TOA due to water vapor changes in response to decreased land albedo occur over the Sahara and Arabian Peninsula, where the response is positive (i.e. more $S W$ absorbed by the enhanced water content; figure $4 c)$. The $L W$ effects of water vapor changes are also positive, but are much more far reaching, spreading over most land and ocean regions of the NH (figure 4d). Averaged globally, the $L W$ 
effects of changes in atmospheric water vapor are as large as the combined direct effect of the albedo forcing and ice-albedo feedback on TOA $S W$, contributing roughly $2 \mathrm{~W} / \mathrm{m}^{2}$ of energy to the Earth system at the TOA (table 1).

\section{4) Temperature FeEdBacks}

Temperature feedbacks are changes in TOA $L W$ due to changes in surface temperature $\left(T_{s}\right)$ and temperatures through the atmospheric column. These combine the Planck and lapse rate feedbacks, with the latter typically having a magnitude that is about one-third that of the former in the global mean (Soden and Held 2006). Using the radiative kernel for temperature, we see that temperature feedbacks produce an increase in outgoing $L W$ that opposes the $S W$ albedo forcing, as expected for negative feedbacks. Changes in $T_{s}$ drive an increase in outgoing $L W$ mostly over $\mathrm{NH}$ land and the Arctic ocean (figure 6a). In contrast, changes in atmospheric temperatures result in more outgoing $L W$ over most land and ocean regions, due to large-scale atmospheric warming as a result of decreasing land albedo (figures $6 \mathrm{~b}, 4 \mathrm{e}$ ). Changes in TOA $L W$ from changing atmospheric temperatures driven by decreased land albedo provide the strongest globally averaged change in the TOA energy budget, yielding a global average of $2.8 \mathrm{~W} / \mathrm{m}^{2}$ of energy loss at the TOA (table 1). The negative Planck and lapse rate feedbacks balance the sum of the forcing and the positive water vapor and albedo feedbacks to achieve TOA energy balance in the new steady state.

\section{5) Cloud Feedbacks}

Cloud feedbacks are changes to net TOA $S W$ and $L W$ as a result of changes in cloud cover and other cloud properties, such as cloud height and optical depth. We consider cloud feedbacks to be locally positive if the change in cloud properties leads to an increase in net energy absorbed at the TOA, given the forcing of reduced albedo. Globally, the combined $S W$ and $L W$ effect of 
changes in cloud cover in response to decreased land albedo is a net loss of energy from the Earth system (figure 4f). Over most land regions, a decrease in land albedo results in an increase in cloud cover that accompanies the precipitation increase (e.g. figure 2c), producing greater reflection of TOA $S W$ (figure $4 \mathrm{~g}$ ) and enhanced $L W$ trapping over land (figure $4 \mathrm{~h}$ ). Some reductions in cloud cover occur over ocean (figure 7a, c), with reduced $S W$ reflection and reduced $L W$ trapping by clouds being especially prominent where reduced rainfall south of the equator accompanies the northward shift of the ITCZ (c.f. figures $2 \mathrm{a}$ and $4 \mathrm{~g}, \mathrm{~h}$ ). The $S W$ and $L W$ effects of cloud changes nearly cancel in regions where high cloud changes accompany ITCZ shifts, while the $S W$ effects of cloud changes dominate in regions where low clouds change (e.g. the upwelling zones in eastern ocean basins). However, in the global mean the effects of cloud changes are negative in both the $L W$ and $S W$, which contribute roughly equally to the global mean cloud feedback (table 1). We note that changes in cloud radiative forcing can actually occur in the absence of any cloud changes, e.g. as a result of changes in surface properties that alter radiative fluxes; such changes in cloud radiative effects are not included in our definition of cloud feedbacks, as detailed in the Appendix and discussed by Soden et al. (2008).

\section{b. Increasing Land Surface Evaporative Resistance}

Unlike decreasing land albedo, which causes more $S W$ energy to be absorbed by land, changing the evaporative resistance of land does not directly modify the total energy absorbed by land. Increasing evaporative resistance drives a repartitioning of surface energy fluxes, where energy previously used to evaporate water is instead partitioned into sensible heat flux or emitted longwave radiation, both of which result from the increase in surface temperature that is driven by the reduced evaporative cooling. While changing the evaporative resistance of the land surface does not directly constitute a radiative forcing as in the albedo simulations, changing terrestrial 
evaporation can lead to changes in surface temperatures, air temperatures, atmospheric moisture, cloud cover, and surface albedo through changes in snow and ice, each of which has an impact on the TOA radiative balance. These atmospheric changes can then feed back on the land surface, resulting in changes in the total amount of energy absorbed (and subsequently released by) the land surface.

Increasing the evaporative resistance of the land surface leads to a reduction in evaporation in regions where there is water stored on the land surface; there is little to no effect of changing this surface property over desert regions (figure 8). Note that the changes in evaporation over land are driven both directly by the increased surface resistance and indirectly by feedbacks with the atmosphere, while the changes in evaporation over ocean areas must be driven indirectly by atmospheric responses to the change in land evaporation. One example of indirectly driven ocean changes is the increase in evaporation downwind of the continents.

Here we discuss the net response to the evaporative resistance forcing, and briefly summarize all of the individual components of that response. In contrast to the response of $T O A_{\text {net }}$ to decreasing land albedo, increasing the evaporative resistance of land results in an increase in $T O A_{\text {net }}$ that is strongest in the northern mid-latitudes during June-August (figure 3b, d).

Increasing the evaporative resistance of land leads to warming by suppressing latent cooling of the land surface, which causes a reduction of snow and sea-ice. This reduces the surface albedo and leads to an increase in absorbed $S W$ at the TOA, mostly in the northern high latitudes during boreal summer (figure 3d, 9b; note the change in color scale in figure 9). There are no statistically significant changes in TOA $S W$ due to changes in atmospheric water vapor, while the $L W$ effects of water vapor changes lead to a slight net increase in energy absorbed by Earth at the TOA (figure $9 \mathrm{c}, \mathrm{d}$, table 1). We note that total column water vapor actually increases over most of the Northern Hemisphere, which has the largest land area (figure 5b). That is, increased land resistance leads 
to decreased land evaporation and less low cloud cover, which drives atmospheric warming; this warming in turn results in more atmospheric water vapor, particularly over the oceans, as the net result of suppressed terrestrial evaporation. Increased surface temperatures in the Arctic lead to more TOA $L W$ loss, while atmospheric warming in the northern mid- to high-latitudes also increases TOA $L W$ loss (figure 9e).

The largest change to TOA radiation as a result of increasing the evaporative resistance of land comes from the $S W$ effects of changes in cloud cover (figure 9f,g). Loss of cloud cover over southeastern North America and western Eurasia results in an increase in $S W$ absorption by Earth. This signal is strongest during NH summer, but persists with weaker magnitude over southeastern North America during NH winter (figure 3d,f). Averaged globally, the $S W$ and $L W$ effects of cloud cover changes on $T O A_{\text {net }}$, resulting from increased land surface evaporative resistance, oppose each other and result in a weak net increase in absorbed energy (table 1).

The high-latitude warming in the increased evaporative resistance simulations is driven by remote atmospheric feedbacks to the imposed change in the land surface. While there is some reduction in evaporation over land in the high latitudes (figure 8) which, with all else held equal, would generate some warming in the high-latitudes, there is also substantial mid-latitude warming due to loss of cloud cover, which is spread over much of the northern mid-to-high latitudes.

\section{c. Pattern Correlation}

The pattern of the total TOA radiative response to a change in albedo or evaporative resistance differs substantially (compare figure $3 \mathrm{a} / \mathrm{b}$ ), with the two having a pattern correlation coefficient of only 0.3 (table 2). However, for particular components of the TOA energy budget decomposition explored above, the pattern is very similar for both forcings. Despite the two land surface properties modifying fundamentally different aspects of the surface energy budget, the pattern of the 
TOA response due to changes in water vapor, surface temperature, air temperature, and snow/ice albedo changes are similar for changes in albedo and evaporative resistance (compare individual panels of figure 4 to those in 9).

Indeed, the pattern of the TOA response due to the $L W$ effects of changes in water vapor, surface temperature, and air temperature are strongly correlated for an imposed change in land surface albedo and land surface evaporative resistance (pattern correlation coefficients range from 0.7 to 0.9 ; table 2). This is because both the water vapor and temperature components of the TOA energy budget decomposition are directly related to warming, and both decreasing the land surface albedo and increasing land surface evaporative resistance lead to large-scale warming of the Earth system. The mechanisms responsible for the surface warming are different; in the case of albedo, warming is the direct result of increased $S W$ absorption at the surface, while in the case of evaporative resistance warming is the result of suppressed evaporative cooling and increased $S W$ absorption due to regional loss of cloud cover. However, in both cases, warming at the surface is accompanied by warming aloft and an increase in atmospheric water vapor over large parts of the northern hemisphere remote from the forcings (figures 2,10 ), presumably due to homogenization of atmospheric temperature and moisture by basic state winds.

The patterns of snow and ice loss for an imposed change in land albedo vs. land evaporative resistance are similar for two reasons. First, only snow/ice covered regions are able to produce this response, and all simulations produce similar patterns of snow and ice cover. Second, both land surface perturbations lead to warming across the Northern Hemisphere, and warming leads to loss of snow and ice.

The TOA responses to our imposed changes in land surface properties can be considered both in terms of adjustments (changes that occur independent of warming) and feedbacks (changes that occur as a result of changes in surface temperature (Sherwood et al. 2015)). For example, 
the imposed increase in evaporative resistance decreases terrestrial evaporation, which on its own could reduce cloud cover and thus impact TOA radiative fluxes. Reducing terrestrial evaporation also leads to surface warming and increased sensible heating from the surface, which could also lead to changes in cloud cover, but in response to the surface warming itself, rather than the change in surface water flux. Our simulations are capturing both the adjustment and feedback components of the response; future work could focus on teasing apart the two responses (e.g. as in Chung and Soden 2015).

\section{d. Attribution of Zonal Mean ITCZ Shift}

In response to both decreased land surface albedo and increased land surface evaporative resistance, there is a northwards shift in the ITCZ (figure 2a,b). Previous studies identified a strong linear relationship between hemispheric energy imbalances, cross-equatorial atmospheric energy transport, and the location of the ITCZ, both in models and in observations (Donohoe et al. 2013), with the ITCZ shifting towards the hemisphere with the positive anomaly of net energy input (Chiang and Bitz 2005; Kang et al. 2008; Swann et al. 2012; Laguë and Swann 2016; Kang 2020).

When land albedo is decreased, the Northern Hemisphere becomes the site of an anomalously positive energy source as a result of increased absorption of $S W$ by the larger land area in the Northern Hemisphere. When land evaporative resistance is increased, loss of low cloud cover in the northern mid-latitudes allows more sunlight to reach the surface over portions of northern midlatitude land, also resulting in an anomalously positive energy source in the Northern Hemisphere. In both cases, the vertically integrated atmospheric energy budget is balanced by a time-mean decrease in atmospheric energy transport from the Southern Hemisphere into the Northern Hemisphere, and a corresponding northwards shift in the zonal mean location of the ITCZ (figure 2). 
The relationship between annual mean cross-equatorial atmospheric energy transport and the zonal mean ITCZ latitude $\phi_{p}$ is strongly linear in our simulations (figure 11). We find a $-4.5^{\circ}$ shift in the ITCZ per $1 \mathrm{PW}$ increase in annual mean northwards cross-equatorial atmospheric energy transport (figure 11). This slope is somewhat larger in magnitude than that found by Donohoe et al. (2013) across CMIP5 models $\left(-2.4^{\circ} \mathrm{PW}\right)$ and from observations of the seasonal cycle in present-day climate $\left(-2.7^{\circ} / \mathrm{PW}\right)$.

The relationship between the zonal mean ITCZ location, $\phi_{p}$, and cross-equatorial atmospheric energy transport, $A E T_{e q}$, in response to perturbed land surface properties is also tightly correlated during Northern Hemisphere summer (figure 11a, c). However, we wish to decompose the ITCZ shift into components associated with individual feedbacks (e.g. water vapor and Planck feedbacks), which requires meridionally integrating the anomalous TOA energy flux due to each feedback to obtain its contribution to the net cross-equatorial energy transport (e.g. Kang et al. 2008; Peterson and Boos 2020); this can only be done exactly in the annual mean, when the transient atmospheric storage term is zero in a steady state climate. In order to leverage our decomposition of the TOA energy budget, we thus focus our analysis of shifts in the ITCZ on the annual mean.

For each component of the TOA energy budget response to changes in land surface albedo and evaporative resistance, we calculate the anomalous cross-equatorial energy flux needed to balance the specific pattern and magnitude of TOA $S W$ and $L W$ change comprising that component. Then, using the linear relationship between cross-equatorial energy transport and $\phi_{p}$, we quantify how much of a shift in the ITCZ we would expect from each individual component of the TOA energy budget response (figure S2 provides a heuristic illustration). Reducing albedo and increasing evaporative resistance both drive northward shifts in cross-equatorial energy transport and the ITCZ (figure 12, dark grey bars), but the processes responsible for these changes differ for the two surface forcings. Since our primary interest is in the relative magnitudes of different feedbacks on 
a given forcing, we rescale the net ITCZ shift produced by each imposed change in land surface property so that it has a value of $+1^{\circ}$ (figure 12 , dark gray bars).

Decreasing land albedo drives a northwards shift in the ITCZ as a result of the direct effect of the imposed change in albedo, with positive (northward) contributions from the albedo feedback due to changes in snow and ice, the $S W$ and $L W$ water vapor feedbacks, and the $L W$ cloud feedback (figure 12). It is notable that the $L W$ cloud effects provide a negative feedback on the global mean TOA energy balance response to the albedo forcing (Table 1) but a positive feedback on the ITCZ response; this is the result of the specific pattern of the $L W$ cloud feedback. Changes in surface temperature, air temperature, and the $S W$ effects of cloud cover changes all act as negative feedbacks that reduce the northward shift of the ITCZ. Of all the feedbacks on the albedo forcing, the Planck feedback is largest, consistent with global mean feedbacks on the $\mathrm{CO}_{2}$ forcing of global mean temperature; water vapor feedbacks are about an order of magnitude larger than the net cloud feedback. The cloud feedbacks seem to be dominated by tropical cloud changes (figure $4 \mathrm{f}, \mathrm{g}, \mathrm{h}$ ) and exhibit strong cancellation between $S W$ and $L W$ components. The effect of all of the feedbacks on the imposed change in land surface albedo largely cancel, such that the actual modelled shift in the ITCZ is comparable to the shift in the ITCZ that would be realized by the $S W$ effects of the imposed change in land surface albedo alone. A similar cancellation of all feedbacks was seen in the one-dimensional energy balance model of Peterson and Boos (2020), although that model used an entirely oceanic lower boundary and did not examine land surface forcings.

Increasing the evaporative resistance of land reduces terrestrial evaporation and leads to warming. There is no directly imposed change in TOA radiation that can be viewed as an imposed forcing, but we are nevertheless able to quantify the contribution of each feedback to the total ITCZ shift. The dominant positive contributors to the northwards shift of the ITCZ in response to increased evaporative resistance are the change in TOA $S W$ due to changes in cloud cover and 
the change in TOA $L W$ due to changes in water vapor. The water vapor-induced $L W$ changes are interesting because they result primarily from increases in humidity over the low-latitude oceans, contrasting with the reduction in land humidity expected to result from an increase in land evaporative resistance. The component that comes closest to constituting a forcing, from the perspective of the energy budget, is the loss of low cloud cover in the northern midlatitudes, which results in a hemispheric energy imbalance with more energy being added to the $\mathrm{NH}$ than the $\mathrm{SH}$ in response to decreased land evaporation. Unlike in the case of albedo, the $L W$ effects of changes in cloud cover act in the same direction as the $S W$ effects, although the $L W$ cloud contribution is relatively small. While changes in tropical clouds dominate the cloud feedbacks in response to a change in land albedo, extra-tropical clouds dominate the cloud feedback in response to changes in land evaporative resistance, with $S W$ cloud effects greatly exceeding any cancellation from $L W$ cloud effects. Changes in TOA $S W$ due to changes in cloud cover alone would result in a roughly $1.6^{\circ}$ northwards shift in the ITCZ, and the $L W$ effect of changes in water vapor would drive an additional $1.7^{\circ}$ northwards shift, but this northwards shift is damped by a strong $3.0^{\circ}$ southward shift resulting from $L W$ feedbacks driven by combined surface and atmospheric warming. While there is a contribution to a northward ITCZ shift from loss of high-latitude snow and ice resulting from warming, this contribution is smaller than the contributions from temperatures, water vapor, and SW cloud feedbacks, and is not statistically significant.

The ITCZ shift predicted by the sum of the feedbacks is larger than the modelled ITCZ shift, more so for evaporative resistance than for albedo (light gray bars in figure 12). This disagreement - and the larger disagreement from the evaporative resistance simulations - is the result of a combination of factors. First, the linear fit used to predict the ITCZ shift associated with a given change in cross-equatorial energy transport has nonzero uncertainty and its central estimate does not perfectly intersect the climatological mean of the three model simulations (compare dashed 
line to large markers in figure 11a). Second, the modelled shift in the ITCZ as a result of the imposed change in land evaporative resistance is quite small compared to the scatter in the points used to construct the linear relationship in figure 11a. Third, because the modelled shift in the ITCZ is smaller than 1-degree, when we rescale the shifts to 1-degree (in figure 12) any initial biases are amplified. However, we also note that since these are rescaled values and the net zonalmean, model-simulated ITCZ shift for the evaporative resistance forcing is only about $0.3^{\circ}$ in a model with a horizontal grid spacing of about $2^{\circ}$, these effects may be negligible compared to discretization and other numerical uncertainties.

\section{e. Clear-sky Linearity Test}

In this study, we heavily rely on the accuracy of the radiative kernel to decompose the TOA response to land surface perturbations into its individual components. Thus, it is worthwhile to check that the kernel is indeed providing an accurate representation of our simulations. To do this, we apply the clear-sky linearity test (Vial et al. 2013), where the modelled change in TOA clearsky (cloud free) fluxes is compared to the clear-sky change in fluxes predicted by the radiative kernel. For both our albedo and evaporative resistance simulations, the modelled clear-sky TOA fluxes agree exceptionally well with the clear-sky fluxes predicted by the radiative kernel (figure 13), which perhaps is not surprising given both the radiative kernel and the simulations explored here use the same atmospheric model.

\section{f. Limitations}

The perturbations made to land surface albedo and evaporative resistance were applied to all non-glaciated land surfaces, and as such the hemispheric imbalance in response to these land surface perturbations is largely a result of the hemispherically asymmetric distribution of the con- 
tinents in their present-day configuration; other patterns of land surface change would yield their own specific patterns of TOA energy flux changes and individual forcing/feedback terms. The spatial extent of the changes imposed here are much larger than any changes associated with anthropogenic land use, and anthropogenic land use is not uniformly distributed over all land areas. Smith et al. (2020) show that the radiative effects of anthropogenic land use across models participating in the Coupled Model Intercomparison Project (CMIP6) are small compared to the radiative effects of $\mathrm{CO}_{2}$ and other forcings. Exploring realistic magnitudes of land use change is important for understanding this aspect of the human-modified climate; the spatial pattern of land use change, on scales both resolved (Winckler et al. 2019) and unresolved (Bonan et al. 1993) by climate models, can also alter regional climate. Here we take the alternate approach of using idealized, high-amplitude land surface forcings; at the very least this avoids the signal being lost in the noise, but this idealized approach also allows us to better understand the physics connecting the land surface to atmospheric processes (Held 2005).

The radiative kernel we use to decompose the TOA energy budget response into its components was generated with the same atmospheric model as we use in this study (CAM5). Any differences in the mean state of atmospheric temperatures, humidity, and cloud cover between the CLM-CAM5 simulation used for the kernels and the baseline SLIM-CAM5 simulation used in this study could introduce errors in the kernel-predicted change in TOA radiation. However, the excellent agreement of the modeled clear-sky TOA fluxes and those predicted by the kernel (figure 13) suggests that any such disagreement would likely be due to clouds, rather than biases in temperatures or moisture. Because we do not have an explicit radiative kernel for cloud fraction, any residuals that may exist in our calculations are lumped in with the impact of clouds on TOA $S W$ and $L W$, by virtue of the methods we use to decompose the TOA energy balance (see Appendix). However, we expect these residuals to be small for two reasons. First, the seasonality and clima- 
tological atmospheric profiles of temperature, humidity, and cloud cover are similar between our SLIM-CAM5 model and the CLM-CAM5 model used to produce the kernels (for a comparison of SLIM-CAM5 to CLM-CAM5, see Laguë et al. 2019). Second, the patterns of $\Delta S W_{\text {cloud }}$ and $\Delta L W_{\text {cloud }}$ strongly resemble the change in cloud fraction in our simulations (where most of the change in cloud fraction occurs in low cloud cover), supporting the idea that they indeed result from changes in cloud cover (c.f. 4f, 7, and 9f).

Another important caveat is that we use a single atmospheric model and a single radiative kernel in this study. While the direct effect of surface albedo on TOA $S W$ radiation under clear-sky conditions is similar across radiative kernels from multiple models (Soden et al. 2008; Shell et al. 2008; Flanner et al. 2011; Pendergrass et al. 2018), the response of cloud cover to a perturbation can vary widely across models (Stocker et al. 2013; Zelinka et al. 2017). Particularly for the evaporative resistance forcing, for which cloud changes are the dominant driver of changes in the TOA radiative budget, other atmospheric models could generate different patterns of TOA $S W$ and $L W$ response. The CAM5 atmospheric model (Neale et al. 2012) used in this study has known biases in both clouds and radiation (see English et al. 2014, and references therein) which could impact our decomposition. Determining how a model bias affects a climate feedback is a difficult problem, but several points can be made. Climate models in general are widely recognized to have strong and often compensating biases in SW and LW cloud forcings (Bogenschutz et al. 2018) that could potentially result in an overestimation of the SW and LW cloud effects in our simulations. Biases in surface albedo (particularly over snow and ice, (English et al. 2014)) in the simulations used to generate the radiative kernels could alter the sensitivity of TOA radiation to imposed albedo changes. However, it is notable that the Planck, water vapor, ice-albedo, and lapse rate feedbacks together exhibit a strong degree of cancellation in their contribution to ITCZ shifts that is similar to that seen in a zonally symmetric idealized model that is highly distinct from 
CAM5 and used clear-sky radiation (Peterson and Boos 2020). This supports the speculation that one should be most concerned about possible model biases in cloud radiative feedbacks on the ITCZ shifts induced by land surface forcings.

The slab ocean used in this study necessarily suppresses any potential responses of ocean circulation and heat transport to changes in land surface properties; in particular, this modeling framework requires the atmosphere to do all the work moving energy within the Earth system in response to a forcing. ITCZ responses to hemispheric energy imbalances are generally damped in models with dynamic oceans vs. models where ocean circulation is held fixed (Green et al. 2019), and as such our simulations may overestimate both the magnitude of the ITCZ shift and the magnitude of the associated TOA radiative response. However, current theory for the damping effect of ocean heat transport on ITCZ shifts (e.g. Schneider 2017) suggests that this damping effect should be strongest for oceanic ITCZ shifts with a lesser influence on precipitation shifts over land. Nevertheless, we recognize that future work using a dynamic ocean model could not only allow for an exploration of how land surface properties modify ocean heat transport and circulation, but could also modify the magnitude and pattern of the atmospheric feedbacks discussed here. Finally, we focused on changes in zonal mean tropical rainfall, and it is known that zonal mean changes are not generally representative of regional precipitation change (Byrne and O'Gorman 2015; Kooperman et al. 2018; Atwood et al. 2020); we leave a detailed exploration of the zonally resolved response for separate work.

\section{Summary and Conclusions}

Changes in both albedo and evaporative resistance of the land surface can drive large changes in the TOA radiation balance. However, the pathways through which these land surface properties modify the TOA radiative budget differ. This study provides a breakdown of the impact of 
individual land surface property changes on TOA radiation, zonally averaged cross-equatorial atmospheric energy transport, and zonal mean ITCZ location. We leverage atmospheric radiative kernels to decompose the effect of decreasing land surface albedo and increasing land surface evaporative resistance on the TOA energy balance.

Decreasing land surface albedo leads to an overall increase in energy absorbed at the TOA over land regions, and a compensating increase in energy lost from the TOA over ocean regions. The surface warming caused by the imposed reduction in surface albedo leads to reduced snow and ice cover that, in turn, cause even more $S W$ to be absorbed by the Earth system. The $L W$ effects of changes in atmospheric water vapor driven by the reduction in land surface albedo also lead to an increase in energy absorbed at the TOA, while warming of surface and air temperatures and changes in cloud cover lead to energy loss from the TOA.

Changes in land surface albedo are strongly attenuated by the atmosphere. That is, for a given change in surface albedo, the change in planetary albedo (the fraction of insolation not absorbed by the climate system) is much smaller (Donohoe and Battisti 2011). Nonetheless, we have demonstrated that changes in land surface albedo can modify TOA net radiation not only directly by modifying the net flux of $S W$ radiation, but also indirectly by modifying atmospheric temperatures, water vapor content, cloud cover, etc. Furthermore, land albedo changes can produce shifts in atmospheric circulations and rainfall, even if their influence on global mean planetary albedo is modest.

Increasing land surface evaporative resistance primarily impacts the TOA radiative budget over northern mid-latitude land regions. The $S W$ effect of changes in cloud cover is the most direct effect of the imposed increase in evaporative resistance, presumably resulting from reductions in cloud cover caused by reduced humidity in the region of the forcing. Planck and water vapor feedbacks act on this forcing in a similar way as for the albedo forcing; these feedbacks are geo- 
graphically remote and have patterns of TOA energy flux change that are highly correlated for the two forcings.

We use the relationship between cross-equatorial energy transport, as diagnosed from TOA energy fluxes, and the zonal mean location of the ITCZ to attribute northward shifts in precipitation to individual surface and atmospheric responses to imposed land surface changes. The combined effect of all atmospheric feedbacks on an imposed change in land surface albedo largely cancel, and the resulting northward shift in the ITCZ is the same shift you would expect from the $S W$ effects of the imposed change in albedo alone. For the imposed increase in evaporative resistance, the $S W$ effect of clouds, combined with albedo changes due to reduced snow and ice cover as a result of warming, results in a net northward shift in the ITCZ. For the evaporative resistance forcing, the $S W$ effect of clouds on ITCZ location is in the opposite direction as the $S W$ effect of clouds for the albedo forcing.

While the idealized nature of these simulations necessarily presents some limitations, it also allows us to disentangle the effect on the atmosphere of individual surface property changes associated with vegetation change. Changes in leaf area index (LAI) can lead to changes in both land surface albedo and land surface evaporative resistance. In complex land surface models, and in the real world, an initial change in climate can lead to a change in LAI; that change in LAI can then, by modifying surface properties and thus surface energy fluxes, lead to a further change in climate, which can further modify LAI, and so on until an equilibrium is reached. This two-way feedback can make it difficult to isolate what the direct effect of a change in LAI is on the climate system. The idealized land surface framework used here allows us to isolate how the climate responds to a given change in albedo or evaporative resistance (such as we might expect from a change in LAI or a change in vegetation cover), without allowing climate feedbacks to modify our imposed surface change. 
These simulations show the atmospheric response to large, idealized perturbations of the land surface. Although these simulations use idealized forcings, the methods we present here allow us to understand the mechanisms through which changes in the land surface drive changes in zonal mean atmospheric circulation and tropical precipitation. Understanding these mechanisms is critical to understanding how changes in the land surface- - both historical and in the futureimpact climate locally and globally.

\section{Data Availability}

The data presented in this paper is archived on Dryad at https://datadryad.org/stash/ dataset/doi:10.6078/D16H6K. The source code for the models used in this study are publicly available on github at https://escomp.github.io/CESM/release-cesm2/downloading_ cesm.html for CESM, and https://github.com/marysa/SimpleLand for SLIM.

Acknowledgments. MML acknowledges postdoctoral funding support from the James S. McDonnell Foundation Postdoctoral Fellowship in Dynamic and Multiscale Systems and NSERC Grant PGSD3-487470-2016. MML and ALSS acknowledge support from NSF Grant 1553715 to the University of Washington. WRB acknowledges support from the U.S. Department of Energy, Office of Science, Office of Biological and Environmental Research, Climate and Environmental Sciences Division, Regional and Global Model Analysis Program, under Award DE-SC0019367. We acknowledge high-performance computing support from Cheyenne (doi:10.5065/D6RX99HX) provided by NCAR's Computational and Information Systems Laboratory, sponsored by the National Science Foundation. We acknowledge additional computing resources from the National Energy Research Scientific Computing Center (NERSC), a U.S. Department of Energy Office of Science User Facility operated under Contract No. DE-AC02$05 \mathrm{CH} 11231$. 


\section{a. TOA Energy Budget}

Decreasing land surface albedo or increasing land surface evaporative resistance modifies the energy balance at the surface $\left(S F C_{n e t}\right)$ and top of atmosphere $\left(T O A_{n e t}\right)$ (equations A1-A2).

$$
\begin{aligned}
T O A_{n e t}= & S W_{T O A}^{\downarrow}-S W_{T O A}^{\uparrow}-L W_{T O A}^{\uparrow} \\
S F C_{n e t}= & S W_{S F C}^{\downarrow}-S W_{S F C}^{\uparrow}+L W_{S F C}^{\downarrow}-L W_{S F C}^{\uparrow} \\
& -S H_{S F C}-L H_{S F C}
\end{aligned}
$$

At the TOA, the energy balance is between incoming shortwave $(S W)$ radiation, reflected $S W$ radiation, and outgoing longwave radiation $(L W)$. At the surface, the balance is between the net flux of $S W$ and $L W$ radiation, and the turblent fluxes of sensible heat $(S H)$ and latent heat $(L H)$. The sign convention in equations A1-A2 is such that $S F C_{n e t}>0$ means more energy absorbed by the surface (land or ocean). Globally averaged, $T O A_{\text {net }}=0$ in the annual mean for our simulations, which are all in equilibrium; spatially, more energy is absorbed by the Earth system in regions with $T O A_{\text {net }}>0$, while more energy is lost by the Earth system in regions with $T O A_{\text {net }}<0$. On land over sufficiently long timescales (e.g. the annual mean, which we examine here), the surface energy budget balances, such that $S F C_{n e t}=0$. The slab ocean model used in these simulations has the same prescribed heat transport across all simulations; $S F C_{n e t}>0$ in regions where the ocean takes up atmospheric energy, and $S F C_{n e t}<0$ in regions where the ocean releases energy to the atmosphere.

Independent of any atmospheric feedbacks, a decrease in land albedo results in more shortwave energy absorbed at the land surface, with a corresponding increase in the upwards surface energy fluxes. In contrast, an increase in land evaporative resistance does not directly change the total amount of energy absorbed or emitted by the land surface; rather, increasing evaporative resistance 
reduces evaporation (i.e. reduces the latent heat flux), while sensible heat and upwards longwave radiation increase to balance the surface energy budget. However, atmospheric responses to land surface changes can modify both the downward fluxes of $S W$ and $L W$ at the surface, and the outgoing fluxes of $S W$ and $L W$ at the TOA.

\section{b. Atmospheric Energy Transport}

We can calculate changes in atmospheric energy transport at the equator using two separate approaches. In the annual mean only, we use changes in $T O A_{n e t}$ and $S F C_{n e t}$ (equation A3) (Lintner et al. 2004).

$$
\begin{aligned}
A E T_{e q} & =\int_{0}^{2 \pi} \int_{-\frac{\pi}{2}}^{0} 2 \pi a^{2} \cos \phi\left(T O A_{n e t}-S F C_{n e t}\right) d \phi d \lambda \\
& =-\int_{0}^{2 \pi} \int_{0}^{\frac{\pi}{2}} 2 \pi a^{2} \cos \phi\left(T O A_{n e t}-S F C_{n e t}\right) d \phi d \lambda
\end{aligned}
$$

$A E T_{e q}>0$ means positive energy transport by the atmosphere from the Southern to Northern Hemisphere. Cross-equatorial atmospheric heat transport can also be calculated directly from the meridional transport of of moist static energy within the atmosphere evaluated at the equator $\langle v h\rangle_{0}$ (equation A4).

$$
\begin{aligned}
\langle v h\rangle_{0} & =\left.\left(\frac{1}{g} \int_{s f c}^{T O A} v h\right)\right|_{l a t=0} \\
h & =c_{p} T+L_{v} Q+g Z
\end{aligned}
$$

where $v$ is the meridional wind and $h$ is the moist static energy. $v h$ is calculated from the heat capacity of dry air $c_{p}$, the latent heat of vaporization $L_{v}$, the meridional atmospheric transport of heat $v T$, the meridional atmospheric transport of moisture $v Q$, and the meridional transport of potential energy $v Z$. In the annual mean, $A E T_{e q}$ calculated from the TOA energy budget is identical to $\langle v h\rangle_{0}$ calculated from vertically integrated atmospheric energy and winds. Both methods give a strongly linear relationship, with roughly $4.2 \mathrm{PW}$ of southwards atmospheric energy transport 
(as calculated by $\langle v h\rangle_{0}$ ) corresponding to a $1^{\circ}$ northwards shift in the ITCZ, and with roughly 4.4 PW of southwards atmospheric energy transport (as calculated from the TOA energy budget) corresponding to a $1^{\circ}$ northwards shift in the ITCZ. However, at sub-annual timescales, heat storage within the surface and the atmosphere cause $A E T$ (implied from the TOA energy budget) to differ substantially from $\langle v h\rangle$ (actual/explicitly calculated atmospheric energy transport). Thus, the relationship between $A E T_{e q}$ and $\phi_{p}$ is only valid at annual mean timescales, while the relationship between $\langle v h\rangle_{0}$ and $\phi_{p}$ is valid on seasonal timescales as well (figure 11). However, we focus on annual mean $A E T_{e q}$ in this study in order to make use of changes in TOA radiation driven by specific atmospheric and surface processes. Each of the individual forcing and feedback terms explored in this study modify the TOA energy imbalance. Using the contribution of each term to $T O A_{\text {net }}$, we leverage equation $\mathrm{A} 3$ to quantify the contribution of each forcing and feedback to $A E T_{e q}$.

\section{c. Radiative kernel calculations}

We use a radiative kernel to diagnose the change in $T O A_{\text {net }}$ resulting from the imposed change in surface albedo, the change in surface albedo resulting from changes in snow and ice, the change in surface temperature, the change in the vertical profile of air temperatures, and the change in the vertical profile of atmospheric water vapor (Soden et al. 2008; Pendergrass et al. 2018). Specifically, we leverage the radiative kernel from Pendergrass et al. (2018), which uses the same atmospheric model (CAM5) as this study. As in Pendergrass et al. (2018), we mask out any changes above the tropopause.

The kernel $K$ gives the change in surface and TOA net $S W$ and/or $L W$ radiation resulting from a $1 \%$ change in surface albedo, a $1 \mathrm{~K}$ change in surface temperature $T_{s}$, a $1 \mathrm{~K}$ change in air temperature $T$ at every vertical model level, and a change in water vapor $q$ at every vertical model level equivalent to a $1 \mathrm{~K}$ increase in air temperature while maintaining constant relative humidity. The 
kernel provides calculations for both "full sky" and "clear sky" conditions. The full sky kernel gives the change in radiative fluxes resulting from each perturbation assuming cloud cover does not change (but still allowing for the effects of climatological cloud cover). The clear sky kernel gives the change in radiative fluxes resulting from each perturbation assuming there are no clouds present. For our calculations, we focus on (a) the full sky radiative kernel and (b) the response of TOA (not surface) $S W$ and $L W$ fluxes.

We use the following notation when referring to calculations using the radiative kernel. The change in net TOA $S W$ as a result of a $1 \%$ change in surface albedo is given by $K_{\alpha}$. The change in net TOA $L W$ resulting from a $1 \mathrm{~K}$ increase in surface temperature is given by $K_{T_{s}}$. The change in TOA $L W$ resulting from a $1 \mathrm{~K}$ increase in air temperature vertically through the atmosphere is given by $K_{T}$. The change in TOA $S W$ and $L W$ resulting from the imposed change in water vapor are given by $K_{q, S W}$ and $K_{q, L W}$, respectively.

We impose a change in snow-free albedo $\Delta \alpha_{i}$ on the land surface. Using $\Delta \alpha_{i}$, we can quantify the change in top of atmosphere $S W$ radiation directly attributable to the imposed change in surface albedo $\Delta S W_{\alpha_{i}}$ (equation A6), where $\Delta \alpha_{i}$ is multiplied by 100 to convert it to a percent value.

$$
\Delta S W_{\alpha_{i}}=K_{\alpha} \times 100 \times \Delta \alpha_{i}
$$

The total modeled change in albedo includes both our imposed snow-free change in albedo as well as albedo changes due to snow and ice responses. We can calculate the change in albedo due to snow and ice changes $\left(\alpha_{S}\right)$ by subtracting the imposed change in albedo $\alpha_{i}$ from the actual modeled change in albedo $\alpha_{m}$ (figure 1 with details in supplement). The change in albedo resulting from changes in snow and ice $\alpha_{s}$ is then multiplied by the radiative kernel to get the change in net TOA $S W$ radiation resulting from albedo changes from snow and ice, $\Delta S W_{\alpha_{s}}$ (equation $\mathrm{A} 7$ ).

$$
\Delta S W_{\alpha_{s}}=K_{\alpha} \times 100 \times \Delta \alpha_{S}
$$


Changes in surface temperature impact net TOA $L W$ radiation; we determine how the specific surface temperature response to each land surface property change impacts TOA $L W\left(\Delta L W_{T_{s}}\right)$ using the radiative kernel for surface temperature (equation A8).

$$
\Delta L W_{T_{s}}=K_{T_{s}} \times \Delta T_{s}
$$

Changes in air temperature throughout the atmospheric column modify both the upwards and downwards flux of $L W$ radiation through the atmosphere. Here, we are specifically interested in how changes in air temperature throughout the atmospheric column modify $L W$ at the TOA $\left(\Delta L W_{T}\right)$. We multiply the radiative kernel for temperature by the change in temperature, then sum over the atmospheric column to get the total effect of the air temperature changes at all vertical levels on TOA $L W$ (equation A9).

$$
\Delta L W_{\Delta T}=\sum_{S F C}^{T O A} K_{T} \times \Delta T
$$

Changes in atmospheric water vapor $q$ modulate both $S W$ and $L W$ radiation. As with changes in $T$, we are interested in the vertical sum of the effect of $\Delta q$ on TOA $S W$ and $L W$. The raw kernel for water vapor $K_{q}$ gives the change in radiative fluxes for the change in $q$ associated with a $1 \mathrm{~K}$ temperature change at constant relative humidity, while our simulations provide us with a $\Delta q$. Thus, we combine the methodology of Pendergrass et al. (2018) and (Shell et al. 2008) to calculate an intermediate kernel $K_{q}^{*}=K_{q} / \frac{\delta q}{\Delta T}$, where $\frac{\delta q}{\Delta T}$ is the change in $q$ that would result from the change in air temperature between our baseline and perturbed simulation ( $T_{0}$ and $T_{1}$, respectively) assuming relative humidity $(\mathrm{RH})$ remained constant, using the saturation vapor pressure $q_{s^{\prime}}$ (that would result from the modelled change in temperature $T_{1}-T_{0}$ at constant $\mathrm{RH}$ ), and the saturation 
vapor pressure $q_{s, 0}$ of the baseline simulation (equations A10-A11).

$$
\begin{aligned}
& K_{q}^{*}=K_{q} / \frac{\delta q}{\Delta T} \\
& K_{q}^{*}=K_{q} /\left(\frac{\ln q_{s^{\prime}, 1}-\ln q_{s, 0}}{T_{1}-T_{0}}\right)
\end{aligned}
$$

772 The natural $\log$ of $q$ is used here as radiation is absorbed by water vapor approximately proportional to $\log q$ (Shell et al. 2008)). We can then use $K_{q}^{*}$ to determine the change in TOA $S W$ and $L W$ attributable to the modelled change in specific humidity $\Delta q$ (equations A12-A15).

$$
\begin{aligned}
\Delta S W_{\Delta q} & =\sum_{S F C}^{T O A}\left(K_{q, S W}^{*} \times \Delta q\right) \\
& =\sum_{S F C}^{T O A}\left(K_{q, S W} \times\left(\ln q_{1}-\ln q_{0}\right) \times \frac{\left(T_{1}-T_{0}\right)}{\left(\ln q_{s, 1}^{\prime}-\ln q_{s, 0}\right)}\right) \\
\Delta L W_{\Delta q} & =\sum_{S F C}^{T O A}\left(K_{q, L W}^{*} \times \Delta q\right) \\
& =\sum_{S F C}^{T O A}\left(K_{q, L W} \times\left(\ln q_{1}-\ln q_{0}\right) \times \frac{\left(T_{1}-T_{0}\right)}{\left(\ln q_{s, 1}^{\prime}-\ln q_{s, 0}\right)}\right)
\end{aligned}
$$

$$
\begin{aligned}
\Delta S W_{\text {cloud }}= & \Delta S W_{\text {model }}-K_{\alpha} \times \Delta \alpha_{i} \\
& -K_{\alpha} \times \Delta \alpha_{s}-\sum_{s f c} K_{q, S W} \times \Delta q
\end{aligned}
$$




$$
\begin{aligned}
\Delta L W_{\text {cloud }}= & \Delta L W_{\text {model }}-K_{T_{s}} \times \Delta T_{s} \\
& -\sum_{s f c}^{\text {toa }} K_{T} \times \Delta T-\sum_{s f c}^{\text {toa }} K_{q, L W} \times \Delta q
\end{aligned}
$$

Because we do not diagnose $\Delta L W_{\text {cloud }}$ or $\Delta S W_{\text {cloud }}$ directly from a cloud kernel, the $\Delta L W_{\text {cloud }}$ or $\Delta S W_{\text {cloud }}$ terms necessarily also include any potential residual terms associated with the kernel. That is, if the actual direct response of TOA $S W$ to $\Delta \alpha_{i}$ in our simulations differs from the $\Delta S W_{\alpha_{i}}$ predicted by $K_{\alpha}$ because, for example, the mean state of cloud cover in our SLIM-CAM5 simulations differs substantially from the mean state of cloud cover in the CLM-CAM5 model, that difference would necessarily be included in the $\Delta S W_{\text {cloud }}$ and $\Delta L W_{\text {cloud }}$ terms here.

We also consider changes in the shortwave cloud forcing ( $S W C F)$ and longwave cloud forcing $(L W C F)$. This is a different quantity than $\Delta S W_{\text {cloud }}$ and $\Delta L W_{\text {cloud }}$ (see, for example, figure 11 in Soden et al. 2008). $\Delta S W_{\text {cloud }}$ and $\Delta L W_{\text {cloud }}$ are the change in TOA $S W$ and $L W$ radiation due to the change in cloud cover resulting from our imposed land surface property change. In contrast, the $S W C F$ and $L W C F$ quantify the difference in TOA $S W$ and $L W$ radiation between cloudy (full sky) and cloud-free (clear sky) conditions (equation A18-A19).

$$
\begin{aligned}
& S W C F=S W_{\text {clearsky }}-S W_{\text {fullsky }} \\
& L W C F=L W_{\text {fullsky }}-L W_{\text {clearsky }}
\end{aligned}
$$

Note the different order of the full sky and clear sky terms for $S W C F$ vs. $L W C F$. This is beause TOA $S W$ (LW) fluxes are, by convention, positive downwards (upwards). This definition of $S W C F$ and $L W C F$ is such that positive values indicate more energy into the system as a result of cloud cover. Over land, $S W C F$ is usually negative because clouds reflect sunlight, while $L W C F$ is usually positive because cloud tops tend to radiate at cooler temperatures than the ground below them. The change in $S W C F$ and $L W C F$ as a result of changes in land surface properties can occur with- 
out any change in cloud cover (e.g. changing land surface albedo modifies $S W_{\text {clearsky }}$ and thus $S W C F)$, but can also occur as a result of changes in cloud cover.

\section{References}

Andrews, T., J. M. Gregory, M. J. Webb, and K. E. Taylor, 2012: Forcing, feedbacks and climate sensitivity in CMIP5 coupled atmosphere-ocean climate models. Geophysical Research Letters, 39 (9), 1-7, doi:10.1029/2012GL051607.

Atwood, A. R., A. Donohoe, D. S. Battisti, X. Liu, and F. S. R. Pausata, 2020: Robust longitudinally-variable responses of the ITCZ to a myriad of climate forcings. Geophysical Research Letters, 47 (17), 1-13, doi:10.1029/2020GL088833.

Bailey, D., E. Hunke, A. DuVivier, B. Lipscomb, C. Bitz, M. Holland, B. Briegleb, and J. Schramm, 2018: CESM CICE5 Users Guide. Tech. rep., 47 pp. URL https://buildmedia. readthedocs.org/media/pdf/cesmcice/latest/cesmcice.pdf.

Betts, A. K., J. H. Ball, A. C. Beljaars, M. J. Miller, and P. A. Viterbo, 1996: The land surfaceatmosphere interaction: A review based on observational and global modeling perspectives. Journal of Geophysical Research Atmospheres, 101 (D3), 7209-7225, doi:10.1029/95JD02135.

Bogenschutz, P. A., A. Gettelman, C. Hannay, V. E. Larson, R. B. Neale, C. Craig, and C.-c. Chen, 2018: The path to CAM6 : coupled simulations with CAM5 . 4 and CAM5 . 5. Geoscientific Model Development, 235-255.

Bonan, G., 2016: Ecological Climatology. 3rd ed., Cambridge University Press, doi:10.1017/ cbo9781107339200.

Bonan, G. B., 2008: Ecological Climatology. Cambridge Univ. Press, Cambridge, UK. 
Bonan, G. B., D. Pollard, and S. L. Thompson, 1992: Effects of boreal forest vegetation on global climate. Nature, 359 (6397), 716-718, doi:Doi10.1038/359716a0.

Bonan, G. B., D. Pollard, and S. L. Thompson, 1993: Influence of Subgrid-Scale Heterogeneity in Leaf Area Index, Stomatal Resistance, and Soil Moisture on Grid-Scale Land-Atmosphere Interactions. Journal of Climate, 6, 1882-1897.

Broccoli, A. J., K. a. Dahl, and R. J. Stouffer, 2006: Response of the ITCZ to Northern Hemisphere cooling. Geophysical Research Letters, 33 (1), 1-4, doi:10.1029/2005GL024546.

Broccoli, A. J., and S. Manabe, 1987: The influence of continental ice, atmospheric CO2, and land albedo on the climate of the last glacial maximum. Climate Dynamics, 1 (2), 87-99, doi: 10.1007/BF01054478.

Budyko, M. I., 1961: The Heat Balance of the Earth's Surface. Soviet Geography, 2 (4), 3-13, doi:10.1080/00385417.1961.10770761.

Budyko, M. I., 1969: The effect of solar radiation variations on the climate of the Earth. Tellus, 21 (5), 611-619, doi:10.3402/tellusa.v21i5.10109.

Budyko, M. I., 1982: The Earth's climate: past and future. The Earth's climate: past and future., doi:10.1016/0004-6981(83)90167-1.

Byrne, M. P., and P. A. O'Gorman, 2015: The response of precipitation minus evapotranspiration to climate warming: Why the "Wet-get-wetter, dry-get-drier" scaling does not hold over land. Journal of Climate, 28 (20), 8078-8092, doi:10.1175/JCLI-D-15-0369.1.

Cess, R. D., and S. D. Goldenberg, 1981: The effect of ocean heat capacity upon global warming due to increasing atmospheric carbon dioxide. Journal of Geophysical Research, 86 (80), 498502. 
Charney, J., W. J. Quirk, S.-H. Chow, and J. Kornfield, 1977: A comparative study of the effects of albedo change on drought in semi-arid regions. doi:10.1175/1520-0469(1977)034〈1366: ACSOTE $\rangle$ 2.0.CO;2.

Charney, J., P. H. Stone, and W. J. Quirk, 1975: Drought in Sahara - Biogeophysical Feedback Mechanism. Science, 187 (4175), 434-435, doi:doi:10.1126/science.187.4175.434.

Chiang, J. C. H., and C. M. Bitz, 2005: Influence of high latitude ice cover on the marine Intertropical Convergence Zone. Climate Dynamics, 25 (5), 477-496, doi:10.1007/s00382-005-0040-5.

Chung, E.-S., and B. J. Soden, 2015: An Assessment of Direct Radiative Forcing, Radiative Adjustments, and Radiative Feedbacks in Coupled Ocean-Atmosphere Models*. Journal of Climate, 28 (10), 4152-4170, doi:10.1175/jcli-d-14-00436.1.

Cvijanovic, I., and J. C. Chiang, 2013: Global energy budget changes to high latitude North Atlantic cooling and the tropical ITCZ response. Climate Dynamics, 40 (5-6), 1435-1452, doi: $10.1007 / \mathrm{s} 00382-012-1482-1$.

Davin, E. L., N. de Noblet-Ducoudré, N. de Noblet-Ducoudre, and N. de Noblet-Ducoudré, 2010: Climatic Impact of Global-Scale Deforestation: Radiative versus Nonradiative Processes. Journal of Climate, 23 (1), 97-112, doi:10.1175/2009JCLI3102.1.

Devaraju, N., N. de Noblet-Ducoudré, B. Quesada, and G. Bala, 2018: Quantifying the relative importance of direct and indirect biophysical effects of deforestation on surface temperature and teleconnections. Journal of Climate, 31 (10), 3811-3829, doi:10.1175/JCLI-D-17-0563.1.

Dickinson, R. E., 1983: Land surface processes and climate—surface albedos and energy balance. Advances in Geophysics, 25 (C), 305-353, doi:10.1016/S0065-2687(08)60176-4. 
Donohoe, A., and D. S. Battisti, 2011: Atmospheric and surface contributions to planetary albedo. Journal of Climate, 24 (16), 4402-4418, doi:10.1175/2011JCLI3946.1.

Donohoe, A., J. Marshall, D. Ferreira, and D. Mcgee, 2013: The relationship between ITCZ location and cross-equatorial atmospheric heat transport: From the seasonal cycle to the Last Glacial Maximum. Journal of Climate, 26 (11), 3597-3618, doi:10.1175/JCLI-D-12-00467.1.

English, J. M., J. E. Kay, A. Gettleman, X. Liu, Y. Wang, Y. Zhang, and H. Chepfer, 2014: Contributions of Clouds, Surface Albedos, and Mixed-Phase Ice Nucleation Schemes to Arctic Radiation Biases in CAM5. Journal of Climate, 27, 5174-5197, doi:10.1175/JCLI-D-13-00608.1.

Flanner, M. G., K. M. Shell, M. Barlage, D. K. Perovich, and M. A. Tschudi, 2011: Radiative forcing and albedo feedback from the Northern Hemisphere cryosphere between 1979 and 2008 . Nature Geoscience, 4 (3), 151-155, doi:10.1038/ngeo1062.

Geen, R., S. Bordoni, D. S. Battisti, and K. Hui, 2020: Monsoons, ITCZs and the Concept of the Global Monsoon. Reviews of Geophysics, 1-45, doi:10.1029/2020rg000700.

Green, B., J. Marshall, and J. Michel, 2019: The 'sticky ' ITCZ : ocean-moderated ITCZ shifts. Climate Dynamics, 53 (1), 1-19, doi:10.1007/s00382-019-04623-5, URL https://doi.org/10. 1007/s00382-019-04623-5.

Held, I. M., 2005: The gap between simulation and understanding in climate modeling. Bulletin of the American Meteorological Society, 86 (11), 1609-1614.

Hurrell, J. W., and Coauthors, 2013: The Community Earth System Model: A Framework for Collaborative Research. Bulletin of the American Meteorological Society, 94 (9), 1339-1360, doi:10.1175/BAMS-D-12-00121.1, URL https://doi.org/10.1175/BAMS-D-12-00121.1.

Kang, S. M., 2020: Extratropical Influence on the Tropical Rainfall Distribution. 1, 24-36. 
Kang, S. M., D. M. W. Frierson, and I. M. Held, 2009: The Tropical Response to Extratropical Thermal Forcing in an Idealized GCM: The Importance of Radiative Feedbacks and Convective Parameterization. Journal of the Atmospheric Sciences, 66 (9), 2812-2827, doi: 10.1175/2009JAS2924.1.

Kang, S. M., I. M. Held, D. M. W. Frierson, and M. Zhao, 2008: The Response of the ITCZ to Extratropical Thermal Forcing: Idealized Slab-Ocean Experiments with a GCM. Journal of Climate, 21 (14), 3521-3532, doi:10.1175/2007JCLI2146.1.

Kooperman, G. J., Y. Chen, F. M. Hoffman, C. D. Koven, K. Lindsay, M. S. Pritchard, A. L. Swann, and J. T. Randerson, 2018: Forest response to rising CO2 drives zonally asymmetric rainfall change over tropical land. Nature Climate Change, 8 (5), 434-440, doi:10.1038/ s41558-018-0144-7, URL http://dx.doi.org/10.1038/s41558-018-0144-7.

Koster, R., and Coauthors, 2004: Regions of Strong Coupling Between Soil Moisture and Precipitation. Science, 305, 1138-1140.

Koster, R. D., and Coauthors, 2006: GLACE: The Global Land-Atmosphere Coupling Experiment. Part I: Overview. Journal of Hydrometeorology, 7 (4), 590-610, doi:10.1175/JHM510.1.

Laguë, M. M., G. B. Bonan, and A. L. S. Swann, 2019: Separating the Impact of Individual Land Surface Properties on the Terrestrial Surface Energy Budget in both the Coupled and Uncoupled Land-Atmosphere System. Journal of Climate, 32 (18), 5725-5744, doi:10.1175/ jcli-d-18-0812.1.

Laguë, M. M., and A. L. Swann, 2016: Progressive midlatitude afforestation: Impacts on clouds, global energy transport, and precipitation. Journal of Climate, 29 (15), 5561-5573, doi:10.1175/ jcli-d-15-0748.1. 
Lawrence, D. M., and Coauthors, 2019: The Community Land Model Version 5: Description of New Features, Benchmarking, and Impact of Forcing Uncertainty. Journal of Advances in Modeling Earth Systems, 11 (12), 4245-4287, doi:10.1029/2018MS001583.

Lee, X., and Coauthors, 2011: Observed increase in local cooling effect of deforestation at higher latitudes. Nature, 479 (7373), 384-387, doi:10.1038/nature10588, URL http://dx.doi.org/10. 1038/nature10588.

Lintner, B. R., A. B. Gilliland, and I. Y. Fung, 2004: Mechanisms of convection-induced modulation of passive tracer interhemispheric transport interannual variability. Journal of Geophysical Research D: Atmospheres, 109 (13), 1-13, doi:10.1029/2003JD004306.

Manabe, S., 1969: Climate and the Ocean Circulation. Monthly Weather Review, 97 (11), 739

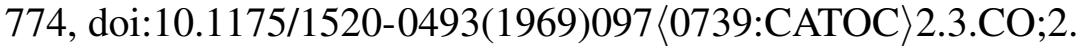

Milly, P. C. D., and a. B. Shmakin, 2002: Global Modeling of Land Water and Energy Balances. Part I: The Land Dynamics (LaD) Model. Journal of Hydrometeorology, 3 (3), 283-299, doi: 10.1175/1525-7541(2002)003〈0283:GMOLWA $\rangle 2.0 . C O ; 2$.

Neale, R. B., and Coauthors, 2012: Description of the NCAR community atmosphere model (CAM 5.0). NCAR Tech. Note NCAR/TN-486+STR.

North, G. R., J. G. Mengel, and D. A. Short, 1983: Simple energy balance model resolving the seasons and the continents: Application to the astronomical theory of the ice ages. Journal of Geophysical Research, 88 (C11), 6576-6586, doi:10.1029/JC088iC11p06576.

Oleson, K. W., and Coauthors, 2013: Technical Description of version 4.5 of the Community Land Model (CLM). NCAR Tech. Note NCAR/TN-503+STR, (July), NCAR/TN-503+STR, 
URL http://www.cesm.ucar.edu/models/cesm1.2/clm/CLM45_Tech_Note.pdfhttp://www.cesm. ucar.edu/models $/$ cesm $1.2 / \mathrm{clm} /$.

Payne, R. E., 1972: Albedo of the Sea Surface. 959-970 pp., doi:10.1175/1520-0469(1972) 029<0959:aotss $\rangle 2.0 . c 0 ; 2$.

Pendergrass, A. G., A. Conley, and F. M. Vitt, 2018: Surface and top-of-Atmosphere radiative feedback kernels for cesm-cam5. Earth System Science Data, 10 (1), 317-324, doi:10.5194/ essd-10-317-2018.

Peterson, H. G., and W. R. Boos, 2020: Feedbacks and eddy diffusivity in an energy balance model of tropical rainfall shifts. npj Climate and Atmospheric Science, 3 (1), 1-10, doi:10. 1038/s41612-020-0114-4, URL http://dx.doi.org/10.1038/s41612-020-0114-4.

Schneider, T., 2017: Feedback of Atmosphere-Ocean Coupling on Shifts of the Intertropical Convergence Zone. Geophysical Research Letters, 44 (22), 644-11, doi:10.1002/2017GL075817.

Sellers, P. J., and Coauthors, 1996: Comparison of radiative and physiological effects of doubled atmospheric CO2 on climate. SCIENCE-NEW YORK THEN WASHINGTON-, 271 (5254), 1402-1405, doi:10.1126/science.271.5254.1402.

Shell, K. M., J. T. Kiehl, and C. A. Shields, 2008: Using the radiative kernel technique to calculate climate feedbacks in NCAR's Community Atmospheric Model. Journal of Climate, 21 (10), 2269-2282, doi:10.1175/2007JCLI2044.1.

Sherwood, S. C., S. Bony, O. Boucher, C. Bretherton, P. M. Forster, J. M. Gregory, and B. Stevens, 2015: Adjustments in the forcing-feedback framework for understanding climate change. Bulletin of the American Meteorological Society, 96 (2), 217-228, doi:10.1175/ BAMS-D-13-00167.1. 
Shukla, J., and Y. Mintz, 1982: Influence of Land-Surface Evapotranspiration on the Earth's Climate. Science, 215 (4539), 1498-1501.

Smith, C. J., and Coauthors, 2020: Effective radiative forcing and adjustments in CMIP6 models. Atmospheric Chemistry and Physics, 20 (16), 9591-9618, doi:10.5194/acp-20-9591-2020.

Soden, B. J., and I. M. Held, 2006: An Assessment of Climate Feedbacks in Coupled OceanAtmosphere Models. Journal of Climate, 19 (14), 3354-3360, doi:10.1175/JCLI3799.1, URL http://dx.doi.org/10.1175/JCLI3799.1.

Soden, B. J., I. M. Held, R. Colman, K. M. Shell, J. T. Kiehl, and C. A. Shields, 2008: Quantifying Climate Feedbacks Using Radiative Kernels. Journal of Climate, 21 (14), 3504-3520, doi:10. 1175/2007JCLI2110.1, URL http://journals.ametsoc.org/doi/abs/10.1175/2007JCLI2110.1http: //dx.doi.org/10.1175/2007JCLI2110.1.

Stocker, T. F., and Coauthors, 2013: Climate change 2013 the physical science basis: Working Group I contribution to the fifth assessment report of the Intergovernmental Panel on Climate Change. Contribution of Working Group I to the Fifth Assessment Report of the Intergovernmental Panel on Climate Change., 9781107057, 1-1535, doi:10.1017/CBO9781107415324.

Swann, A. L. S., I. Y. Fung, and J. C. H. Chiang, 2012: Mid-latitude afforestation shifts general circulation and tropical precipitation. Proceedings of the National Academy of Sciences, 109 (3), 712-716, doi:10.1073/pnas.1116706108.

Vial, J., J. L. Dufresne, and S. Bony, 2013: On the interpretation of inter-model spread in CMIP5 climate sensitivity estimates. Climate Dynamics, 41 (11-12), 3339-3362, doi:10.1007/ s00382-013-1725-9. 
Winckler, J., Q. Lejeune, C. H. Reick, and J. Pongratz, 2019: Nonlocal Effects Dominate the Global Mean Surface Temperature Response to the Biogeophysical Effects of Deforestation. Geophysical Research Letters, 46 (2), 745-755, doi:10.1029/2018GL080211.

Winckler, J., and Coauthors, 2018: Different response of surface temperature and air temperature to deforestation in climate models. Earth System Dynamics Discussions, 1-17, doi:10.5194/ esd-2018-66.

Zarakas, C. M., A. L. Swann, M. M. Laguë, K. C. Armour, and J. T. Randerson, 2020: Plant Physiology Increases the Magnitude and Spread of the Transient Climate Response to CO2 in CMIP6 Earth System Models. Journal of Climate, 33 (19), 8561-8578, doi:10.1175/jcli-d-20-0078.1.

Zelinka, M. D., D. A. Randall, M. J. Webb, and S. A. Klein, 2017: Clearing clouds of uncertainty. Nature Climate Change, 7 (10), 674-678, doi:10.1038/nclimate3402. 


\section{LIST OF TABLES}

Table 1. Table of the globally averaged annual mean (and standard deviation) of the components of the TOA energy budget breakdown. Mean values are bold where they exceed the standard deviation. All fluxes in this table are considered positive downwards, such that a positive (negative) value means a net gain (loss) of energy at the TOA due to each component.

Table 2. Pattern correlation between the TOA energy budget response to each individual forcing and feedback term, calculated using the area-weighted Pearson-r correlation coefficient. Note that (a) this only accounts for correlation between the pattern of the TOA response to each surface property, and not the intensity, and (b) the imposed albedo change is zero everywhere for a change in land surface evaporative resistance. 


\begin{tabular}{|c|c|c|c|c|c|c|c|c|c|c|c|}
\hline & \multicolumn{11}{|c|}{ Decrease in land albedo: } \\
\hline & $d T O A_{\text {net }}$ & $d S W_{T O A, n e t}$ & $d L W_{T O A, \text { net }}$ & $d S W_{\alpha_{i}}$ & $d S W_{\alpha_{s}}$ & $d S W_{q}$ & $d L W_{q}$ & $d L W_{T_{s}}$ & $d L W_{T}$ & $d S W_{\text {clouds }}$ & $d L W_{\text {clouds }}$ \\
\hline mean & 0.08 & 2.03 & -1.95 & 1.60 & 0.52 & 0.16 & 1.8 & -0.72 & -2.77 & -0.26 & -0.27 \\
\hline \multirow[t]{3}{*}{ std } & 0.65 & 0.38 & 0.39 & 0.04 & 0.10 & 0.02 & 0.36 & 0.06 & 0.55 & 0.37 & 0.21 \\
\hline & \multicolumn{11}{|c|}{ Increase in land evaporative resistance } \\
\hline & $d T O A_{n e t}$ & $d S W_{\text {model }}$ & $d L W_{\text {model }}$ & $d S W_{\alpha_{i}}$ & $d S W_{\alpha_{s}}$ & $d S W_{q}$ & $d L W_{q}$ & $d L W_{T_{s}}$ & $d L W_{T}$ & $d S W_{\text {clouds }}$ & $d L W_{\text {clouds }}$ \\
\hline mean & 0.04 & 0.85 & -0.81 & 0 & 0.15 & 0.04 & 0.44 & -0.27 & -0.8 & 0.66 & -0.18 \\
\hline std & 0.62 & 0.4 & 0.37 & 0 & 0.08 & 0.03 & 0.37 & 0.06 & 0.53 & 0.40 & 0.18 \\
\hline
\end{tabular}

TABLE 1. Table of the globally averaged annual mean (and standard deviation) of the components of the TOA energy budget breakdown. Mean values are bold where they exceed the standard deviation. All fluxes in this table are considered positive downwards, such that a positive (negative) value means a net gain (loss) of energy at the TOA due to each component. 


\begin{tabular}{|l|l|}
\hline TOA Breakdown Term & Pattern Correlation \\
\hline Albedo (Snow/Ice) & 0.66 \\
\hline SW Water vapor & 0.29 \\
\hline LW Water vapor & 0.69 \\
\hline LW from Surface Temperature & 0.73 \\
\hline LW from Column Air Temperature & 0.87 \\
\hline SW Cloud Effects & 0.34 \\
\hline LW Cloud Effect & 0.45 \\
\hline Total TOA SW Response & 0.48 \\
\hline Total TOA $L W$ Response & 0.52 \\
\hline Total TOA net Response & 0.33 \\
\hline
\end{tabular}

TABLE 2. Pattern correlation between the TOA energy budget response to each individual forcing and feedback term, calculated using the area-weighted Pearson-r correlation coefficient. Note that (a) this only accounts for correlation between the pattern of the TOA response to each surface property, and not the intensity, and (b) the imposed albedo change is zero everywhere for a change in land surface evaporative resistance. 


\section{LIST OF FIGURES}

Fig. 1. Effective changes in albedo resulting from an imposed 0.1 decrease in snow-free land albedo in the visible SW spectrum. (a) Modelled change in annual mean clear-sky surface albedo (imposed and snow albeo effects). (b) Change in surface albedo resulting from changes in snow cover only (change in albedo when the snow depth is $\geq 0.1 \mathrm{~m}$ of snow-water equivalent). (c) Effective change in imposed albedo (total albedo change - snow albedo change). (d) Same as (c), but with a narrower range of albedos to show the small spatial variation of the imposed snow-free change in albedo.

Fig. 2. Annual mean change in surface temperature (top) and precipitation (bottom) for deceased land surface albedo (left) and increased land surface evaporative resistance (right). Only values with $p<0.05$ in a student's t-test are shown for the maps.

Fig. 3. Total change in net TOA $S W+L W$ as a result of decreasing land albedo (left column) and increasing land evaporative resistance (right column) for (a) the annual mean, (b) June-JulyAugust, and (c) December-January-February. The global mean value $\left[\mathrm{W} / \mathrm{m}^{2}\right]$ of the change in net TOA radiation is noted to the lower left of each panel. Only values that differ with $p<0.05$ in a students' t-test are shown.

Fig. 4. Change in annual mean net top of atmosphere energy fluxes $\left[\mathrm{W} / \mathrm{m}^{2}\right]$ as a result of decreasing land surface albedo. All fluxes (SW and LW) are shown positive down such that red colours indicate more energy absorbed by the Earth system, while blue colours indicate more energy lost by the Earth system. (a) shows the change in TOA net $S W$ radiation from the imposed change in albedo. (b) shows change in TOA net $S W$ radiation from albedo changes to do changes in snow and ice. (c) and (d) show, respectively, changes in TOA $S W$ and $L W$ radiation from changes in column water vapor. (e) shows change in TOA $L W$ from combined changes in the surface radiative temperature and changes in air temperature. (f) shows the total change in TOA $S W+L W$ from changes in cloud cover. The effect of cloud cover is separated into its impact on TOA $S W$ in (g) and TOA $L W$ in (h). The area-weighted global mean value for each term is shown to the lower left of each map. Only values that differ with $p<0.05$ in a students' t-test are shown.

Fig. 5. Change in annual mean total column precipitable water $\left[\mathrm{kg} / \mathrm{m}^{2}\right]$ for (a) a decrease in land surface albedo and (b) an increase in land surface evaporative resistance. Only values that differ with $p<0.05$ in a students' t-test are shown.

Fig. 6. Change in annual mean TOA $L W$ resulting from a decrease in land surface albedo attributed to (a) changes in surface temperature and (b) changes in atmospheric temperatures. Only values that differ with $p<0.05$ in a students' t-test are shown.

Fig. 7. Change in low cloud fraction $(a, b)$ and total cloud fraction $(c, d)$ for an imposed decrease in land albedo (left) and imposed increase in evaporative resistance (right). Only values that pass a student's t-test with $p<0.05$ are shown.

Fig. 8. Change in surface latent heat flux from increased terrestrial evaporative resistance, where brown indicates less evaporation when land evaporative resistance is high, and blue indicates more evaporation when land evaporative resistance is high. Only values that pass a student's t-test with $p<0.05$ are shown.

Fig. 9. Same as figure 4, but for an increase in land surface evaporative resistance. Note that in this case, there is no imposed change in land surface albedo. 
Fig. 10. Change in zonally averaged, annual mean temperature (a,b) and specific humidity (c,d), for a decrease in land albedo $(a, c)$ and an increase in land evaporative resistance $(b, d)$. Only values that pass a student's t-test with $p<0.05$ are shown.

Fig. 11. Relationship between the zonal-mean latitude of the ITCZ (measured as the center of mass of tropical precipitation $\phi_{p}$ ) and the magnitude of cross-equatorial energy flux (in PW). The relationship is shown for (a) the annual mean, (b) December/January/February, and (c) June/July/August. Each small dot represents the annual average of a single year from 3 30-year model runs: a "baseline" simulation with a global land albedo of $\alpha=0.2$ and evaporative resistance of $r_{s}=100 \mathrm{~s} / \mathrm{m}$, a dark land simulation with $\alpha=0.1$, and a high evaporative resistance run with $r_{s}=200 \mathrm{~s} / \mathrm{m}$. The large grey circle shows the multi-year average of the baseline $\left(\alpha=0.2, r_{s}=100 \mathrm{~s} / \mathrm{m}\right)$ simulation, while the black square and red triangle show the multi-year average of the dark $\left(\alpha=0.1, r_{s}=100 \mathrm{~s} / \mathrm{m}\right)$ and high evaporative resistance $\left(\alpha=0.2, r_{s}=200 \mathrm{~s} / \mathrm{m}\right)$ simulations, respectively. The slope of the linear relationship between cross-equatorial atmospheric energy transport calculated using the TOA energy imbalance and the ITCZ location is noted in the upper right of each panel, while the same relationship calculated using vertically integrated moist static energy and meridional winds is noted in brackets.

Fig. 12. The breakdown of the change in the zonally averaged annual mean location the ITCZ (measured by $\phi_{p}$ ) resulting from each component, rescaled to a $1^{\circ}$ total northwards shift. Solid (hatched) bars show the change in the zonal mean ITCZ location for a uniform decrease of land surface albedo (increase of evaporative resistance). From left to right, bars show: the total modelled change (dark grey); the change due to the sum of all of the individual components (light gray); the change attributable to the imposed change in albedo (oragne), the change in albedo due to changes in snow and ice (yellow), $L W$ effects due to changes in surface temperature (dark purple), $L W$ effects to due vertical changes in the atmospheric temperature profile (lilac), $S W$ changes due to changes in water vapor (light green), $L W$ changes due to changes in water vapor (dark green), $S W$ changes due to changes in cloud cover (light blue), and $L W$ changes due to changes in cloud cover (dark blue). The magnitude of the ITCZ shift is noted above each bar, as well as the p value taken from a students' t-test, where $p<0.05$ indicates a significant shift from the baseline simulation.

Fig. 13. Zonal mean change in TOA clear-sky radiation directly from the model (gray lines) and predicted by the clear-sky radiative kernel (red lines) for (a) the dark-bright simulations and (b) the high-low evaporative resistance simulations. The global mean disagreement shows the area-weighted difference in TOA clearsky fluxes for the explicitly modelled minus kernel-predicted methods. Shading shows \pm 1 standard deviation of the annual mean values. 

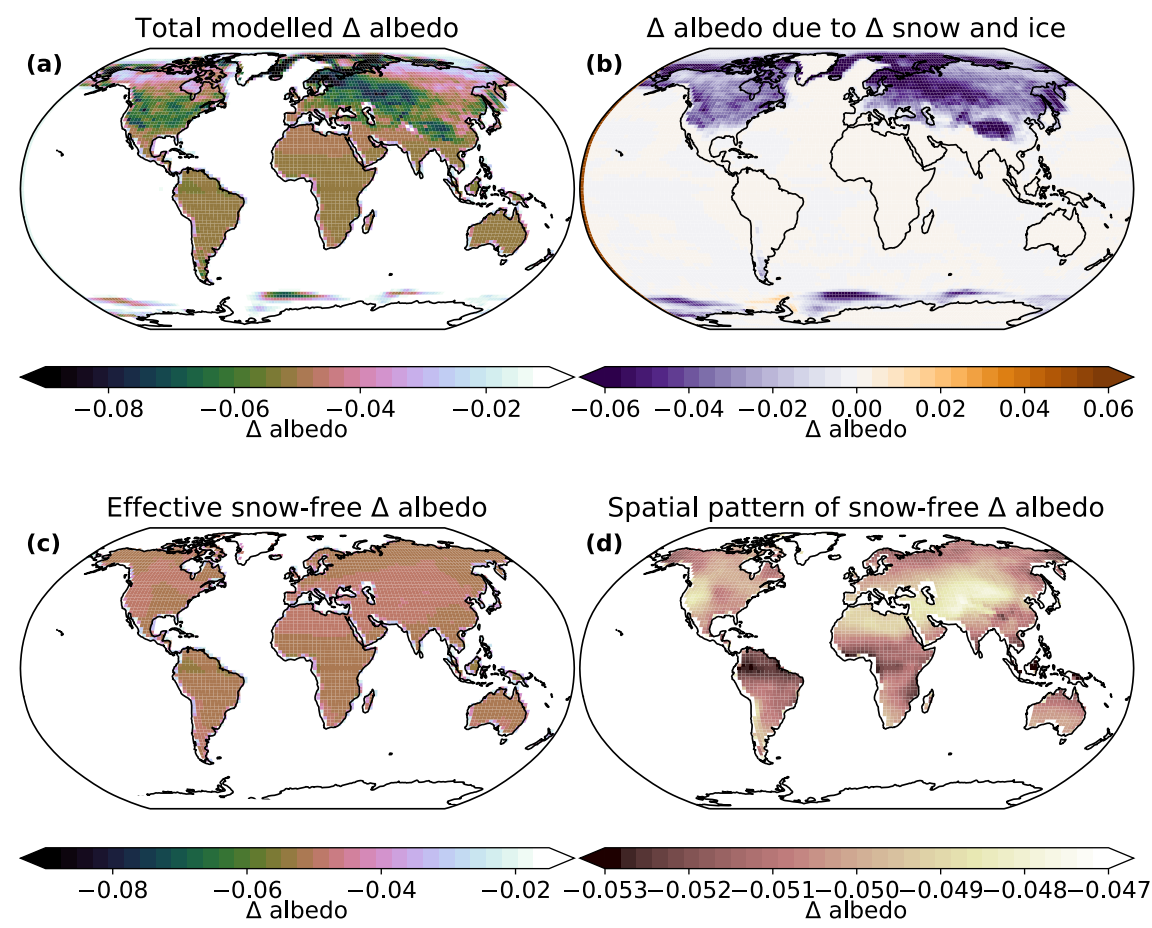

FIG. 1. Effective changes in albedo resulting from an imposed 0.1 decrease in snow-free land albedo in the visible SW spectrum. (a) Modelled change in annual mean clear-sky surface albedo (imposed and snow albeo effects). (b) Change in surface albedo resulting from changes in snow cover only (change in albedo when the snow depth is $\geq 0.1 \mathrm{~m}$ of snow-water equivalent). (c) Effective change in imposed albedo (total albedo change - snow albedo change). (d) Same as (c), but with a narrower range of albedos to show the small spatial variation of the imposed snow-free change in albedo. 

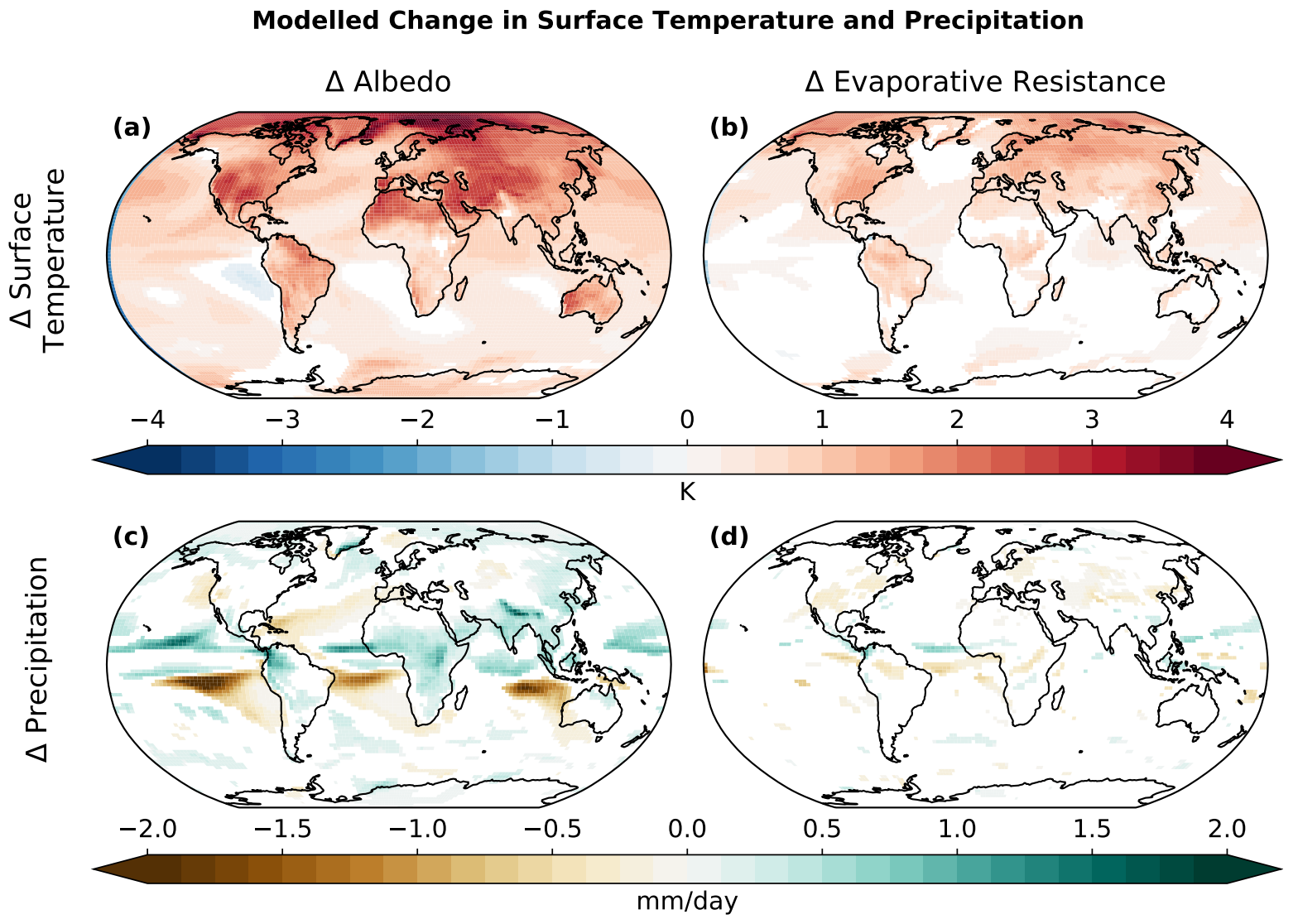

FIG. 2. Annual mean change in surface temperature (top) and precipitation (bottom) for deceased land surface albedo (left) and increased land surface evaporative resistance (right). Only values with $p<0.05$ in a student's t-test are shown for the maps. 

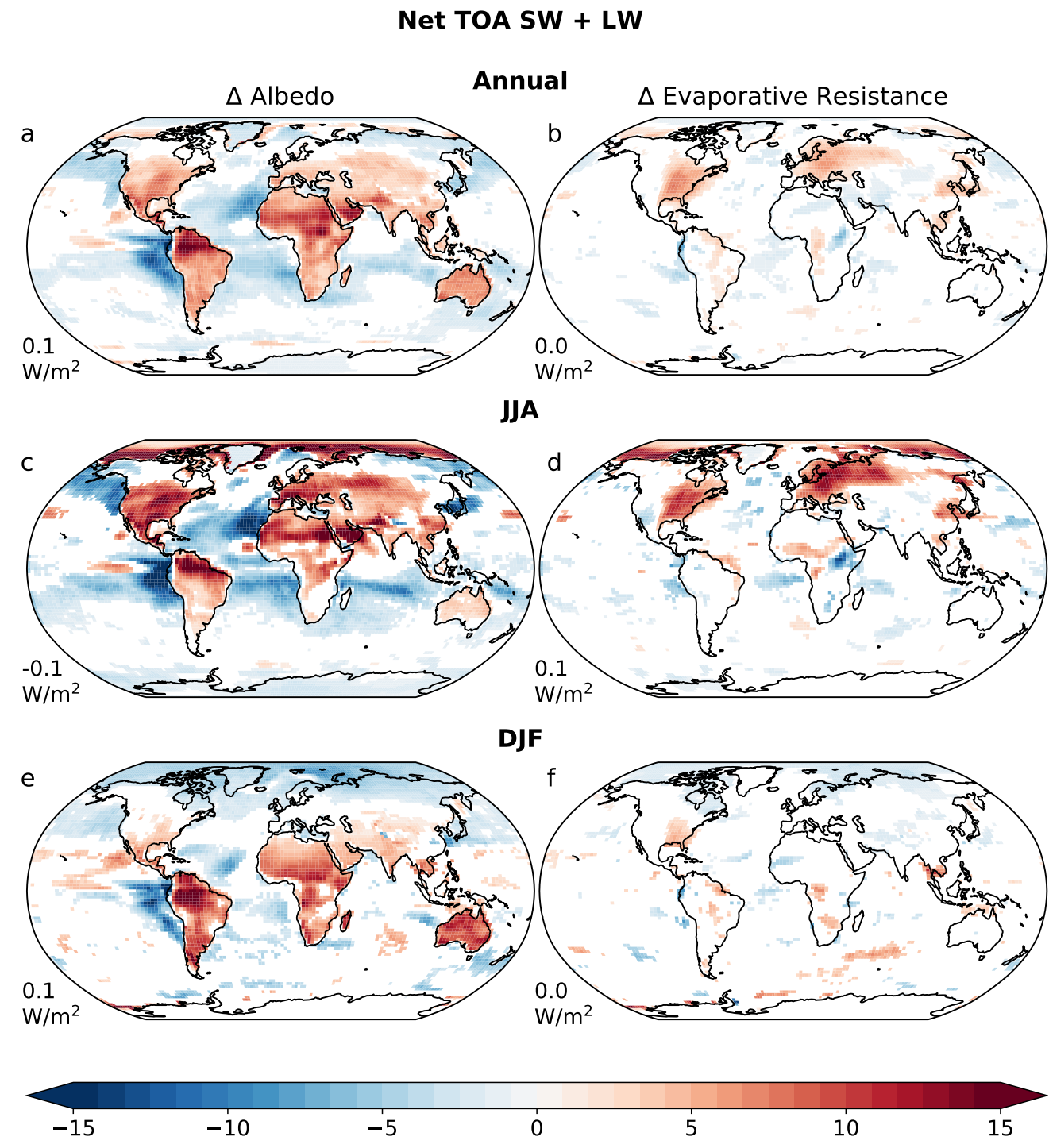

FIG. 3. Total change in net TOA $S W+L W$ as a result of decreasing land albedo (left column) and increasing land evaporative resistance (right column) for (a) the annual mean, (b) June-July-August, and (c) December-

January-February. The global mean value $\left[\mathrm{W} / \mathrm{m}^{2}\right]$ of the change in net TOA radiation is noted to the lower left of each panel. Only values that differ with $p<0.05$ in a students' t-test are shown. 


\section{Net TOA flux breakdown, decrease in land albedo ANN}

$\triangle \mathrm{SW}$ (Imposed Albedo)

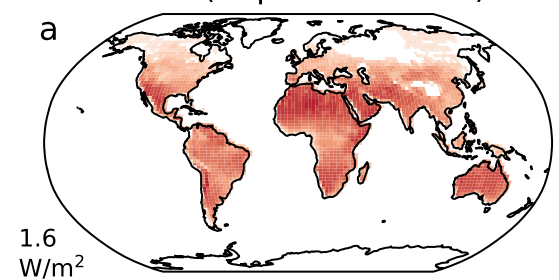

$\triangle \mathrm{SW}$ from Changes in $Q$

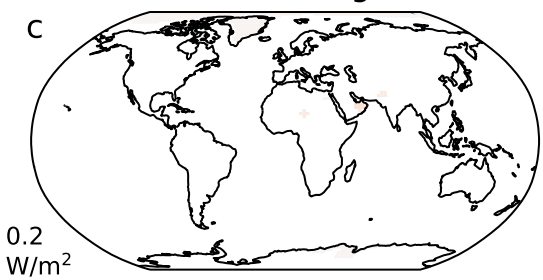

$\triangle \mathrm{LW}$ from Changes in $T$

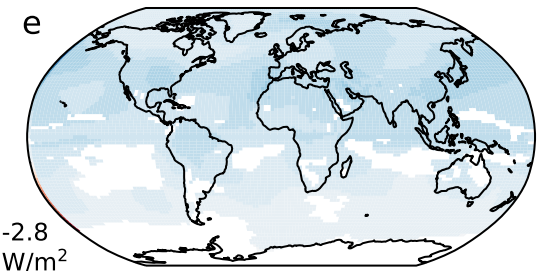

$\triangle \mathrm{SW}$ from Changes in Clouds

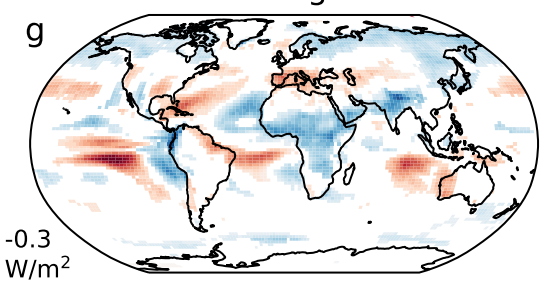

$\triangle \mathrm{SW}$ (Snow \& Ice Changes)

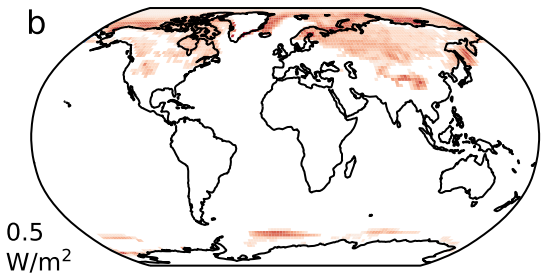

$\triangle \mathrm{LW}$ from Changes in $Q$

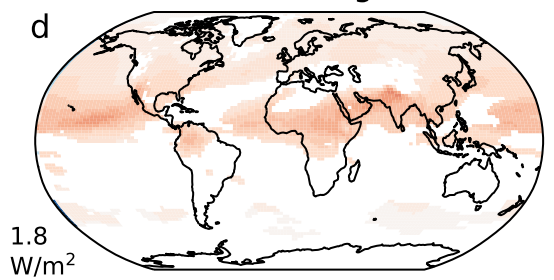

$\triangle \mathrm{SW}+\mathrm{LW}$ from Changes in Clouds

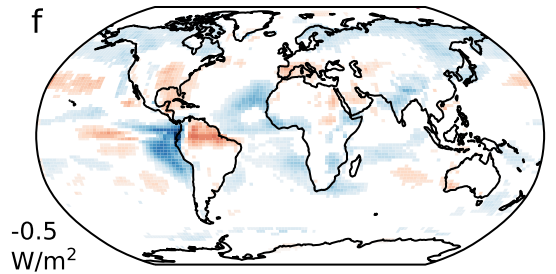

$\Delta$ LW from Changes in Clouds

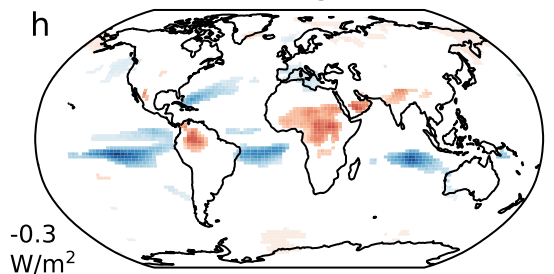

FIG. 4. Change in annual mean net top of atmosphere energy fluxes $\left[\mathrm{W} / \mathrm{m}^{2}\right]$ as a result of decreasing land surface albedo. All fluxes (SW and LW) are shown positive down such that red colours indicate more energy absorbed by the Earth system, while blue colours indicate more energy lost by the Earth system. (a) shows the change in TOA net $S W$ radiation from the imposed change in albedo. (b) shows change in TOA net $S W$ radiation from albedo changes to do changes in snow and ice. (c) and (d) show, respectively, changes in TOA $S W$ and $L W$ radiation from changes in column water vapor. (e) shows change in TOA $L W$ from combined changes in the surface radiative temperature and changes in air temperature. (f) shows the total change in TOA $S W+L W$ from changes in cloud cover. The effect of cloud cover is separated into its impact on TOA $S W$ in (g) and TOA $L W$ in (h). The area-weighted global mean value for each term is shown to the lower left of each map. Only values that differ with $p<0.05$ in a students' t-test are shown. 


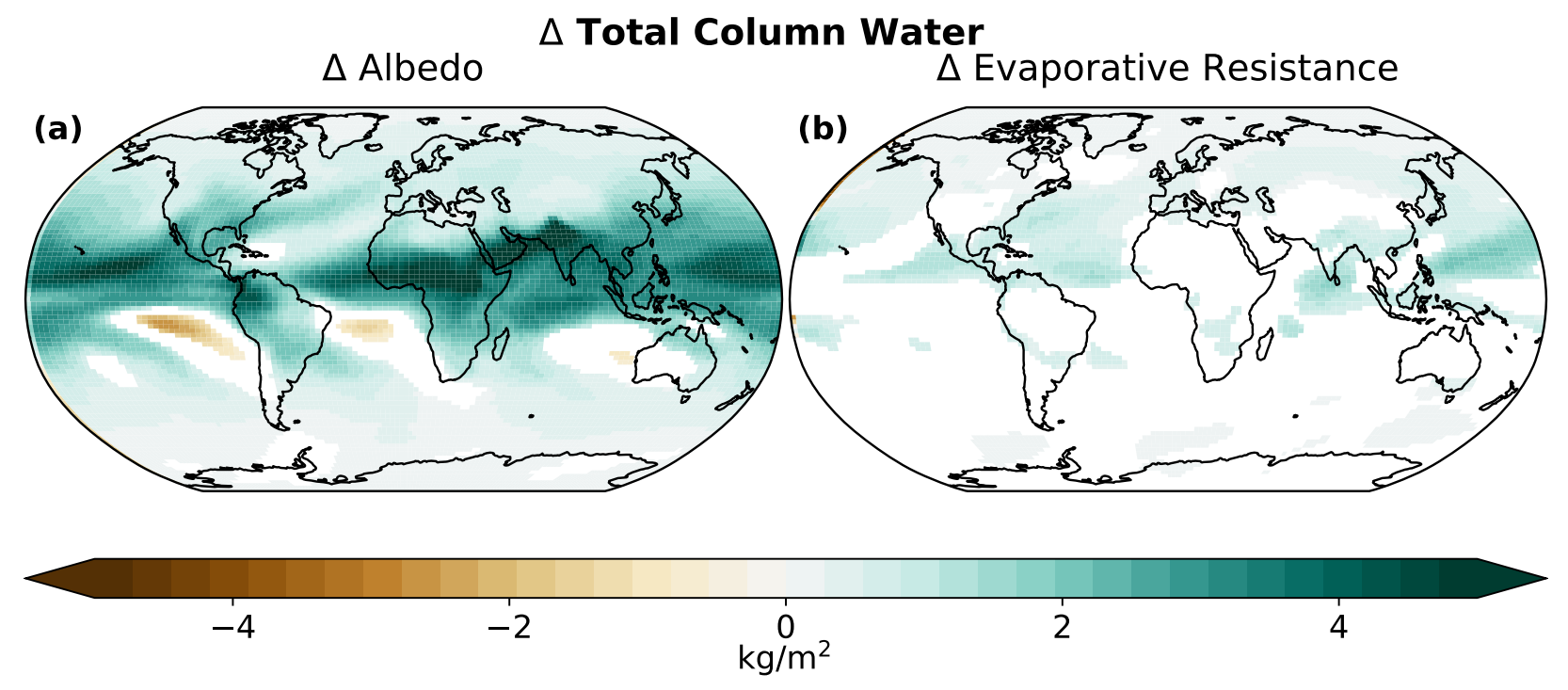

FIG. 5. Change in annual mean total column precipitable water $\left[\mathrm{kg} / \mathrm{m}^{2}\right]$ for (a) a decrease in land surface albedo and (b) an increase in land surface evaporative resistance. Only values that differ with $p<0.05$ in a students' t-test are shown. 

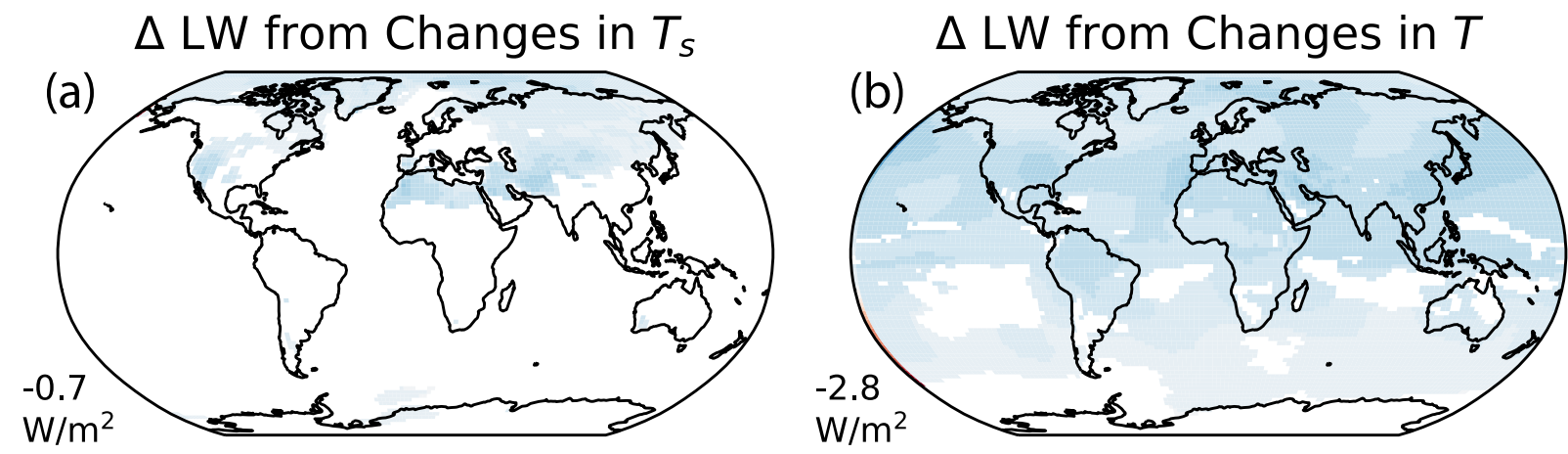

FIG. 6. Change in annual mean TOA $L W$ resulting from a decrease in land surface albedo attributed to

(a) changes in surface temperature and (b) changes in atmospheric temperatures. Only values that differ with $p<0.05$ in a students' t-test are shown. 


\section{Change in Modelled Cloud Fraction}
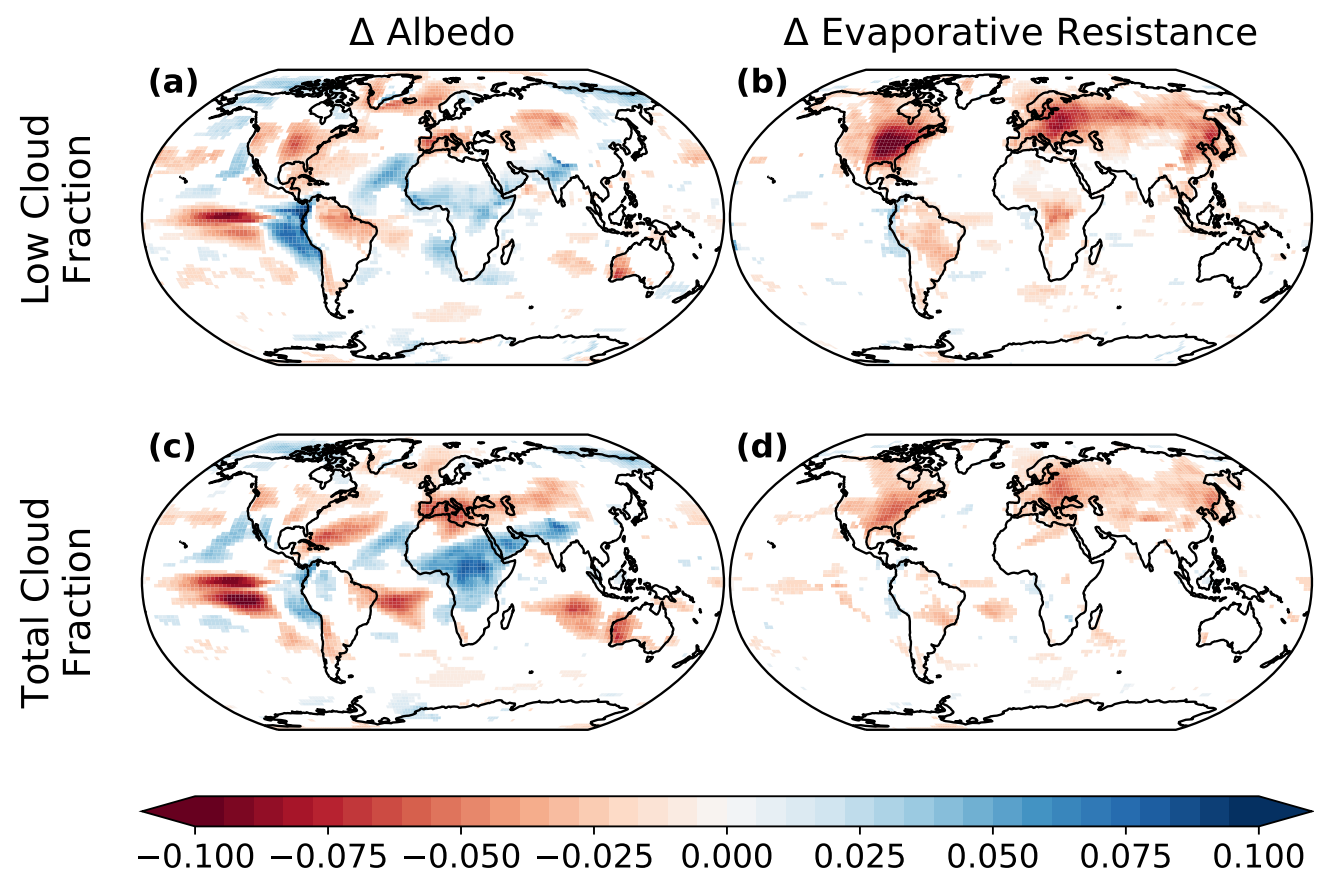

FIG. 7. Change in low cloud fraction $(a, b)$ and total cloud fraction $(c, d)$ for an imposed decrease in land $p<0.05$ are shown. 


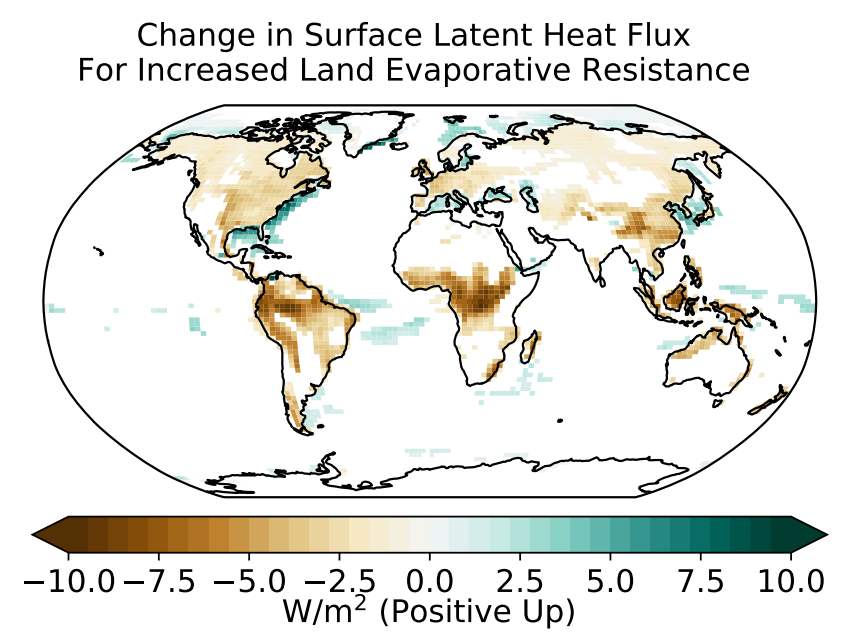

FIG. 8. Change in surface latent heat flux from increased terrestrial evaporative resistance, where brown indicates less evaporation when land evaporative resistance is high, and blue indicates more evaporation when land evaporative resistance is high. Only values that pass a student's t-test with $p<0.05$ are shown. 


\section{Net TOA flux breakdown, increase in land evaporative resistance (ANN)}

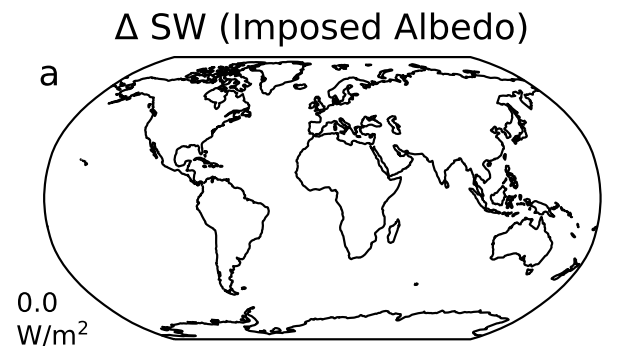

$\Delta \mathrm{SW}$ (Snow \& Ice Changes)
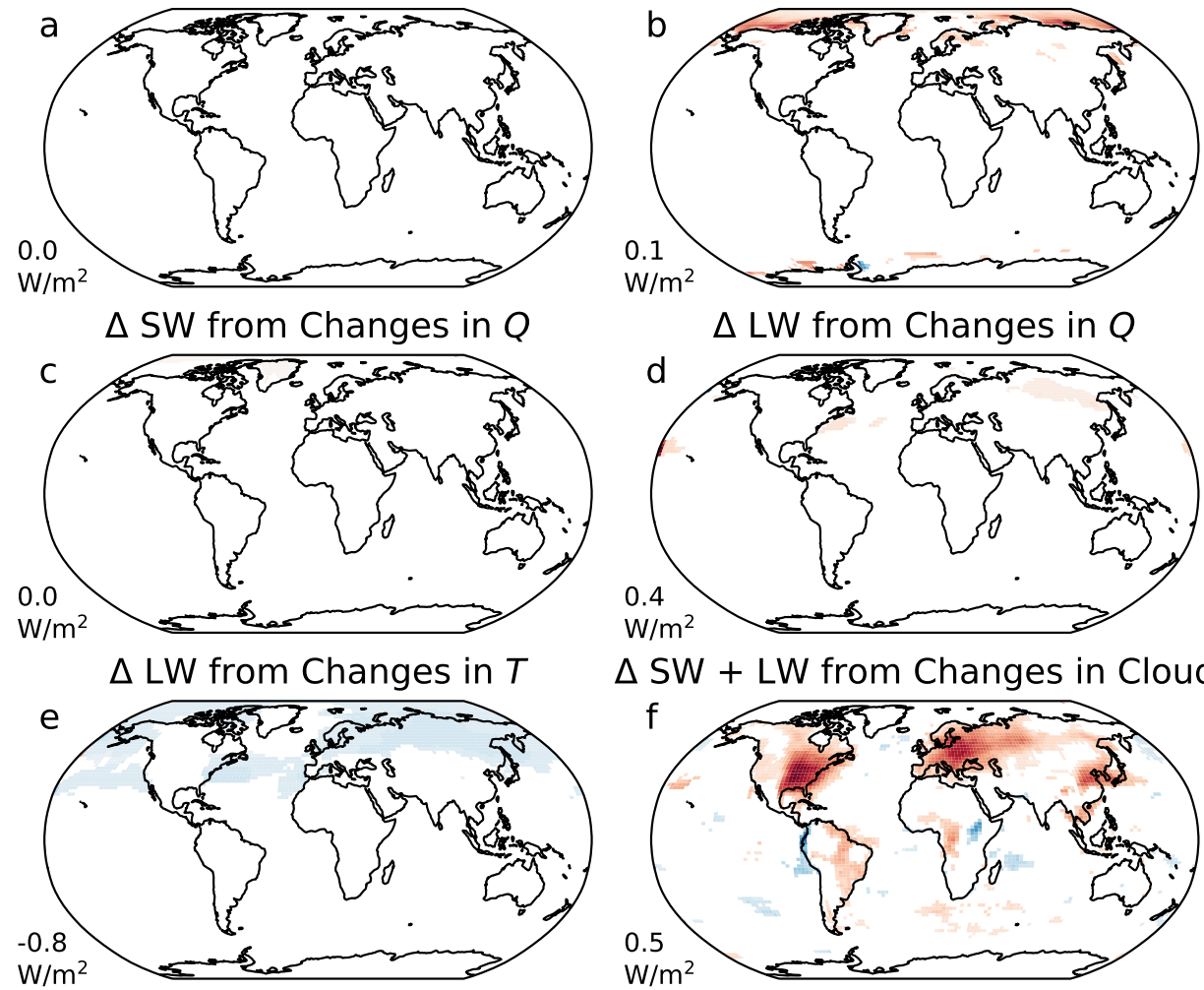

$\Delta \mathrm{SW}+\mathrm{LW}$ from Changes in Clouds

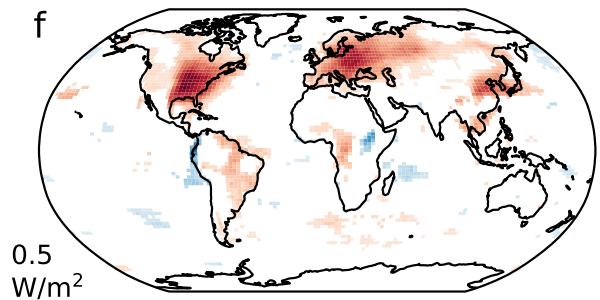

$\triangle \mathrm{SW}$ from Changes in Clouds

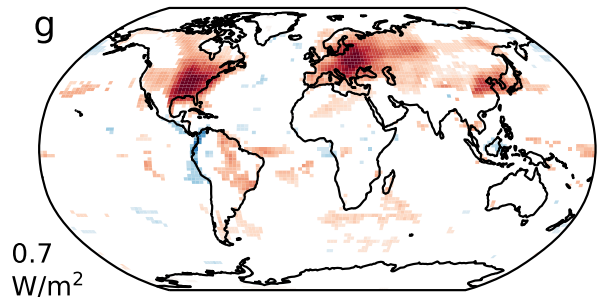

$\Delta \mathrm{LW}$ from Changes in Clouds
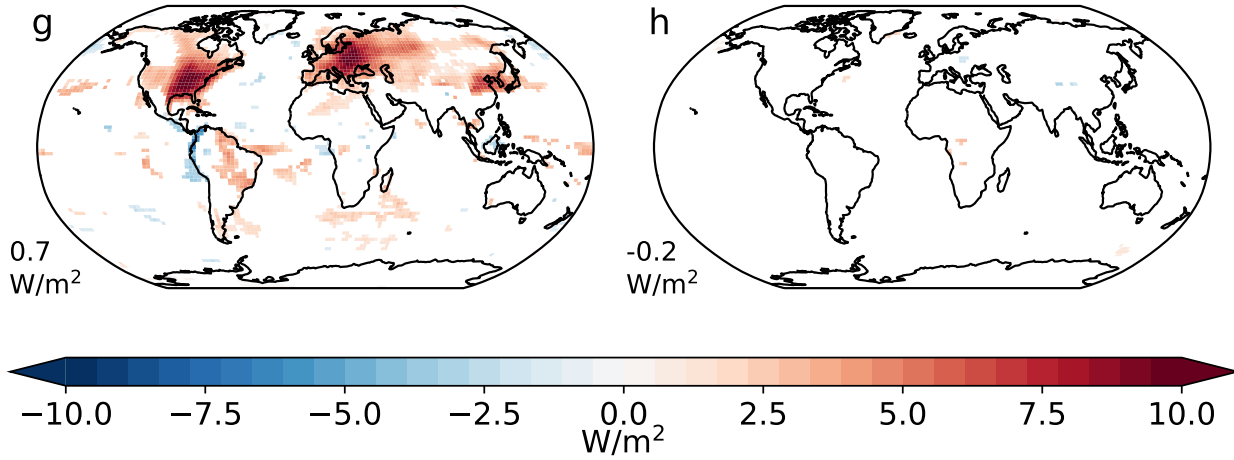

FIG. 9. Same as figure 4, but for an increase in land surface evaporative resistance. Note that in this case, there is no imposed change in land surface albedo. 

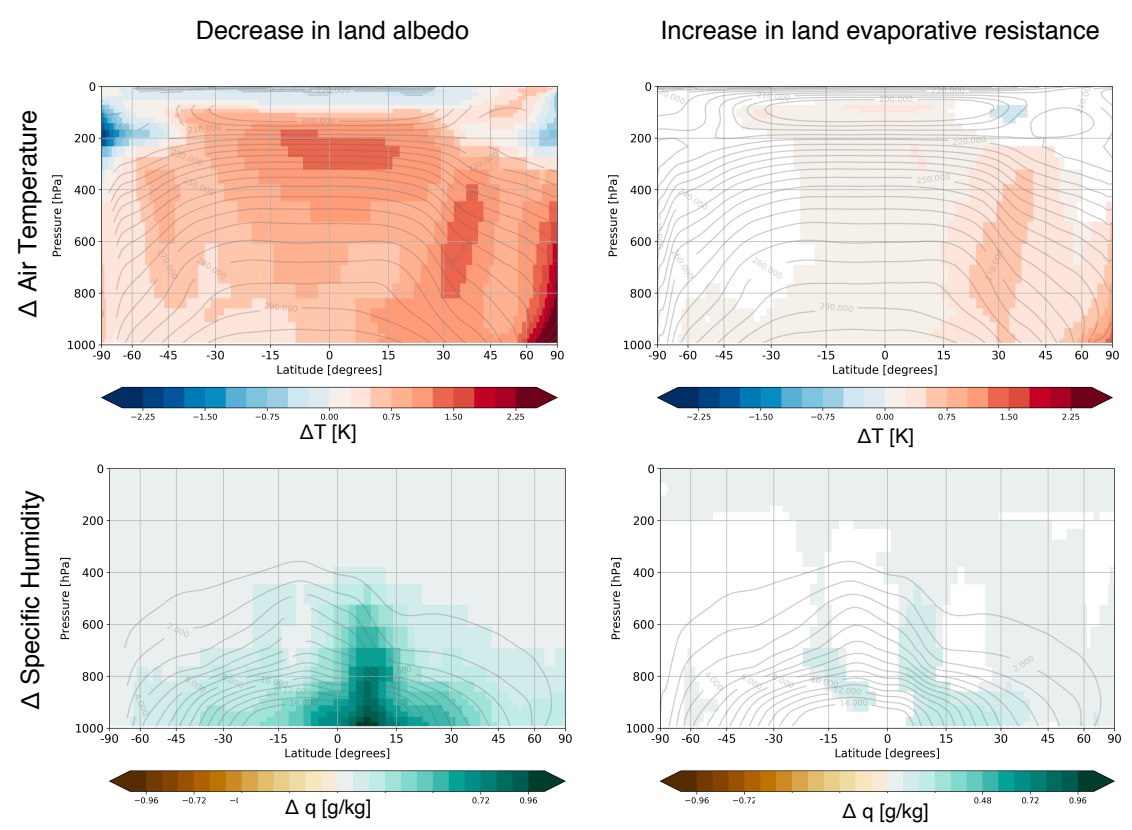

FIG. 10. Change in zonally averaged, annual mean temperature $(a, b)$ and specific humidity $(c, d)$, for a decrease in land albedo $(a, c)$ and an increase in land evaporative resistance $(b, d)$. Only values that pass a student's t-test with $p<0.05$ are shown. 

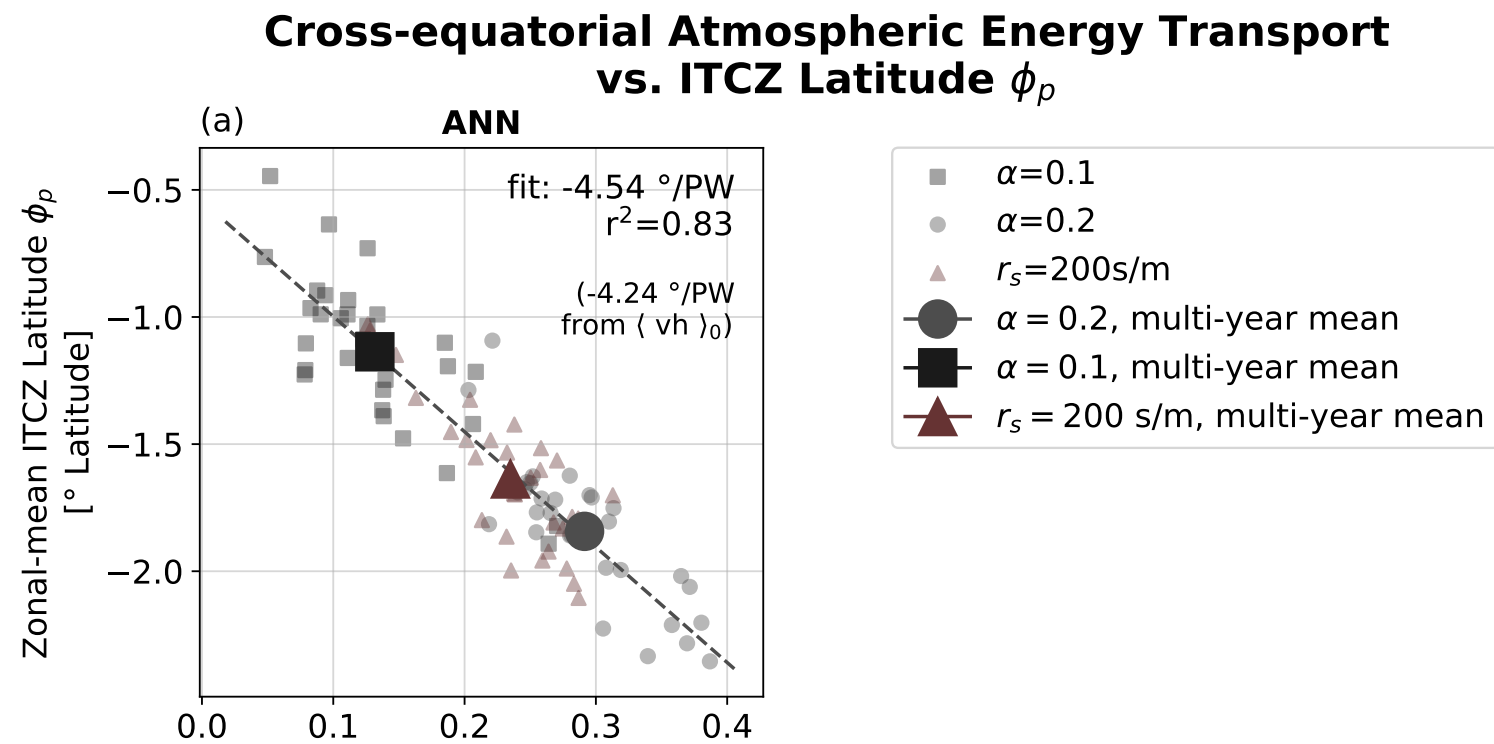

Cross-equatorial energy transport [PW]

(b)

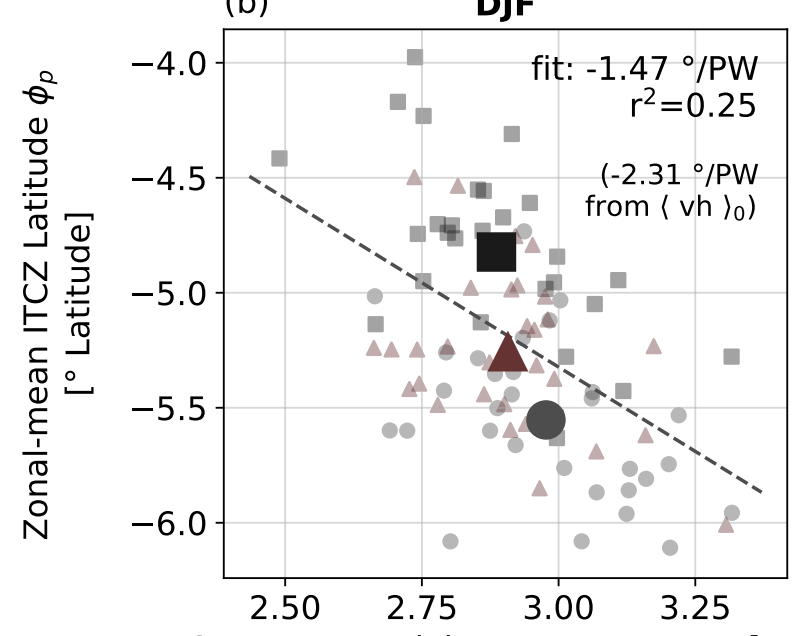

Cross-equatorial energy transport [PW]

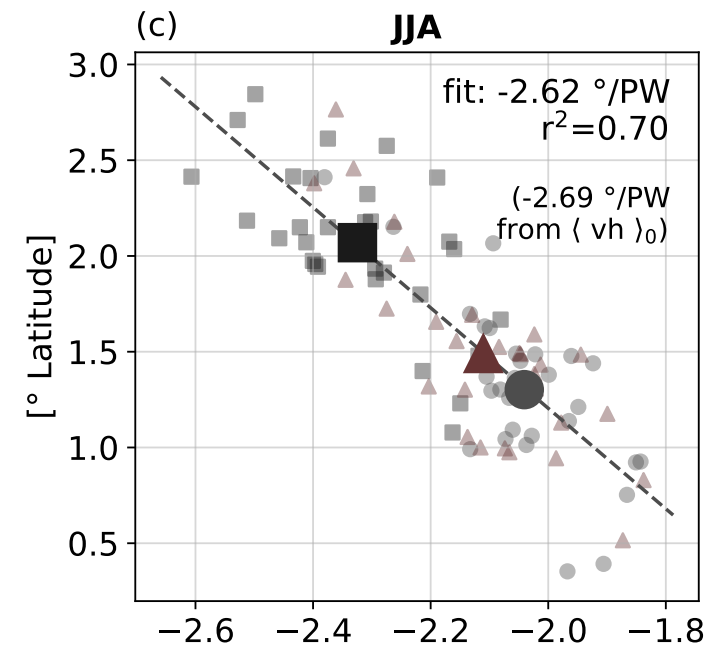

Cross-equatorial energy transport [PW]

FIG. 11. Relationship between the zonal-mean latitude of the ITCZ (measured as the center of mass of tropical precipitation $\phi_{p}$ ) and the magnitude of cross-equatorial energy flux (in PW). The relationship is shown for (a) the annual mean, (b) December/January/February, and (c) June/July/August. Each small dot represents the annual average of a single year from 3 30-year model runs: a "baseline" simulation with a global land albedo of $\alpha=0.2$ and evaporative resistance of $r_{s}=100 \mathrm{~s} / \mathrm{m}$, a dark land simulation with $\alpha=0.1$, and a high evaporative resistance run with $r_{s}=200 \mathrm{~s} / \mathrm{m}$. The large grey circle shows the multi-year average of the baseline $\left(\alpha=0.2, r_{s}=100 \mathrm{~s} / \mathrm{m}\right)$ simulation, while the black square and red triangle show the multi-year average of the dark $\left(\alpha=0.1, r_{s}=100 \mathrm{~s} / \mathrm{m}\right)$ and high evaporative resistance $\left(\alpha=0.2, r_{s}=200 \mathrm{~s} / \mathrm{m}\right)$ simulations, respectively. The slope of the linear relationship between cross-equatorial atmospheric energy transport calculated using the TOA energy imbalance and the ITCZ location is noted in the upper right of each panel, while the same relationship calculated using vertically integrated moist static energy and meridional winds is noted in brackets. 


\section{Attribution of $\triangle$ ITCZ Location $\phi_{p}$ from Each TOA Breakdown Component (ANN)}

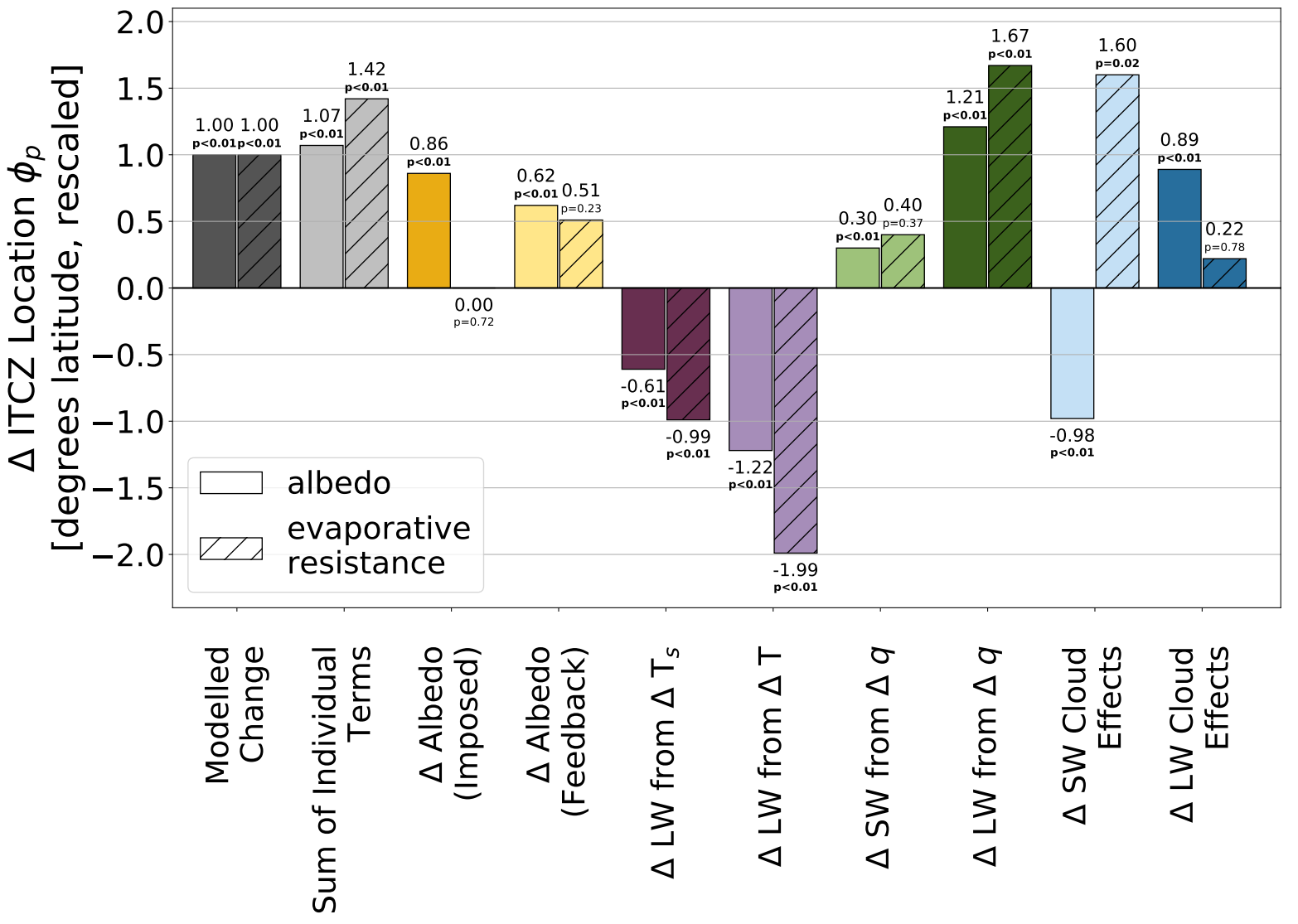

FIG. 12. The breakdown of the change in the zonally averaged annual mean location the ITCZ (measured by $\phi_{p}$ ) resulting from each component, rescaled to a $1^{\circ}$ total northwards shift. Solid (hatched) bars show the change in the zonal mean ITCZ location for a uniform decrease of land surface albedo (increase of evaporative resistance). From left to right, bars show: the total modelled change (dark grey); the change due to the sum of all of the individual components (light gray); the change attributable to the imposed change in albedo (oragne), the change in albedo due to changes in snow and ice (yellow), $L W$ effects due to changes in surface temperature (dark purple), $L W$ effects to due vertical changes in the atmospheric temperature profile (lilac), $S W$ changes due to changes in water vapor (light green), $L W$ changes due to changes in water vapor (dark green), $S W$ changes due to changes in cloud cover (light blue), and $L W$ changes due to changes in cloud cover (dark blue). The magnitude of the ITCZ shift is noted above each bar, as well as the p value taken from a students' t-test, where $p<0.05$ indicates a significant shift from the baseline simulation. 


\section{$\triangle$ Clear-sky TOA Fluxes, Model vs. Kernel \\ (Clear-sky Linearity Test)}
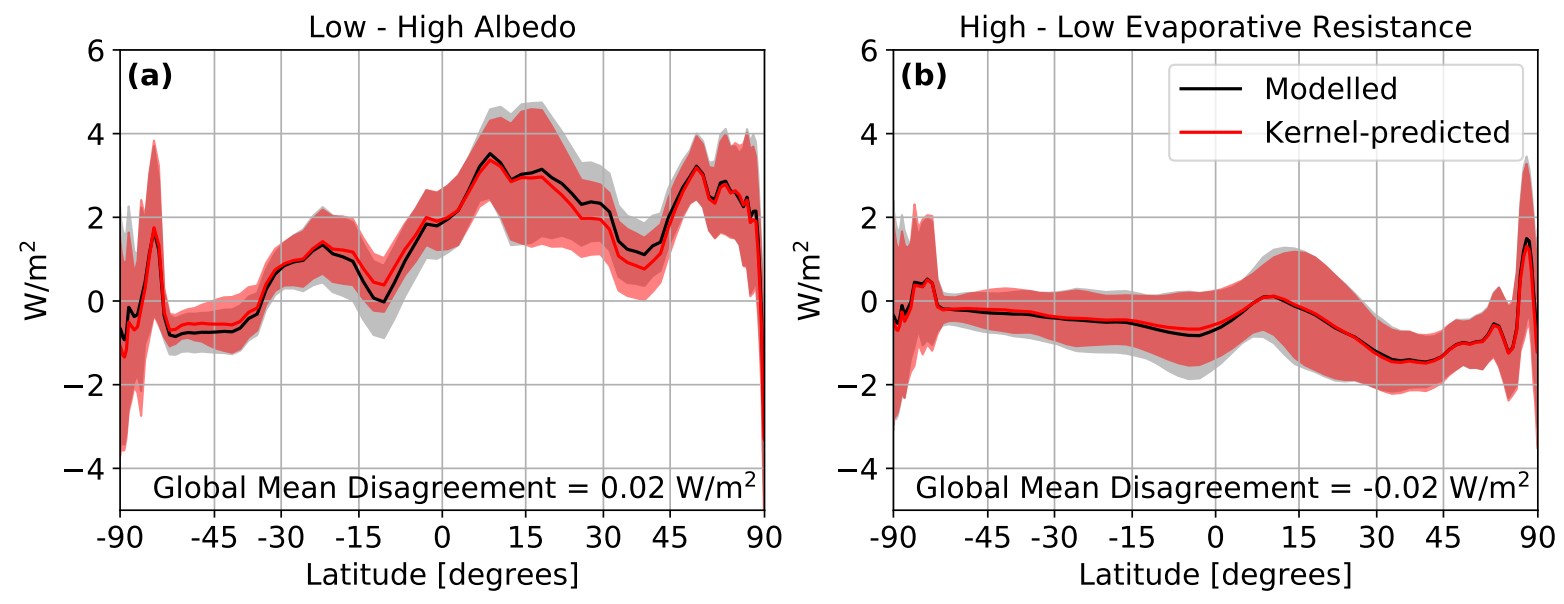

FIG. 13. Zonal mean change in TOA clear-sky radiation directly from the model (gray lines) and predicted by the clear-sky radiative kernel (red lines) for (a) the dark-bright simulations and (b) the high-low evaporative fluxes for the explicitly modelled minus kernel-predicted methods. Shading shows \pm 1 standard deviation of the annual mean values. 